Portland State University

PDXScholar

6-11-1986

\title{
A Comparison of Behavioral Problems Between Speech and/or Language Impaired Children and Normal Children
}

Jeannie S. Botelho

Portland State University

Follow this and additional works at: https://pdxscholar.library.pdx.edu/open_access_etds

Part of the Child Psychology Commons, and the Speech Pathology and Audiology Commons Let us know how access to this document benefits you.

Recommended Citation

Botelho, Jeannie S., "A Comparison of Behavioral Problems Between Speech and/or Language Impaired Children and Normal Children" (1986). Dissertations and Theses. Paper 3519.

https://doi.org/10.15760/etd.5403

This Thesis is brought to you for free and open access. It has been accepted for inclusion in Dissertations and Theses by an authorized administrator of PDXScholar. Please contact us if we can make this document more accessible: pdxscholar@pdx.edu. 
AN ABSTRACT OF THE THESIS OF Jeannie S. Botelho for the Master of Science in Speech Communication: emphasis in Speech Pathology and Audiology presented June 11, 1986.

Title: A Comparison of Behavioral Problems between Speech and/or Language Impaired Children and Normal Children

APPROVED BY THE MEMBERS OF THE THESIS COMMITTEE:

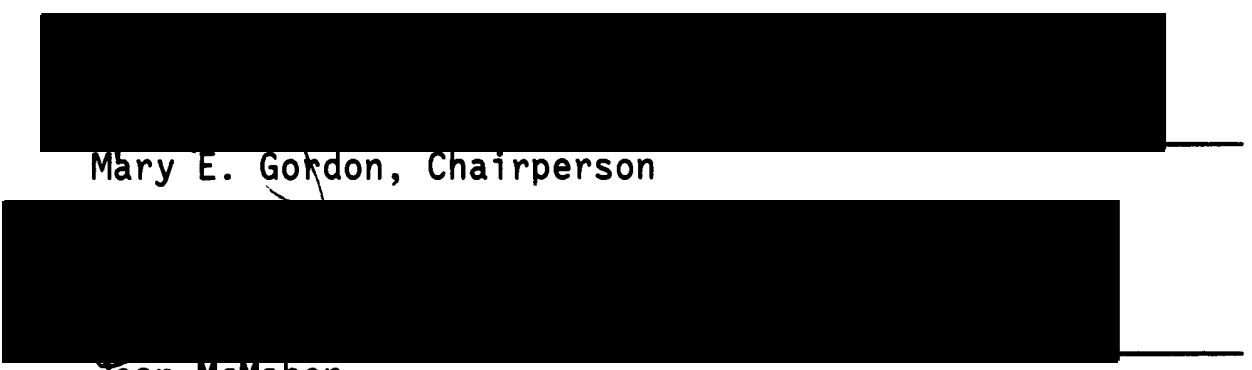

Joan McMahon

Language is a complex communication system which distinguishes human beings from other species. It is the primary medium through which individuals function and interact in their environment. If a child has any difficulties developing an effective mode of communication, it would seem likely other areas of his or her development could be adversely affected. There is extensive research which shows speech and language disordered children are at risk for behavioral, social and emotional problems (Cantwell and Baker, 1977). It has been suggested at least 50 percent of speech and/or language impaired children may have behavioral problems severe enough as to warrant a definable psychiatric diagnosis (Cantwell et al., 1979). However, it is difficult to assess if this is an accurate prevalence figure 
because of methodological problems. Their research included speech and/or language impaired children with other handicapping conditions (e.g., autism and mental retardation), so the difficulty then is deciding which handicap is associated with the behavioral problems, the autism/mental retardation or the speech and language impairment. Also, they drew their subjects from a community speech and hearing clinic, a setting which may not reflect a "typical" speech and language impaired population. This research was designed to obtain behavioral data on children, who were selected from a public school setting whose primary handicapping condition was speech and/or language impairment, and then compare them to their "normal" peers. This could provide further information to substantiate the claims that a speech and/or language impaired population do in fact have a higher prevalence of behavioral problems.

The questions posed in this study were: 1) Is there a significant difference in the prevalence of behavioral problems between speech and/or language impaired children and normal children as reported by parents and teachers? and 2) Is there a significant difference in the types of behavioral problems between speech and/or language impaired children and normal children, as reported by parents and teachers?

Thirty-eight children between the ages of 5 and 11 participated in this study. The subjects included 19 speech and/or language impaired children and 19 normal children. There were 14 boys and 5 girls in each group. Information regarding the 38 subjects' behavior was obtained by using the parent and teacher reported Child Behavior Checklists developed by Achenbach and Edelbrock (1983). 
Results were analyzed by comparing the raw scores in each group on the behavior problem scales, the number of behavior problem items, total behavior problem score, the social competence scale and the adaptive functioning scale. The data for the boys and girls were analyzed separately, as the raw scores were computed on different Child Behavior Profiles. Further analyses were completed on the boys by dividing them into 3 groups: speech impaired only; a combined speech and language, and language impaired group; and the control group of normal boys. These analyses were not completed for the girls due to the small number of subjects. Analysis of variance (Anova) and a Tukey post hoc analysis were used to determine whether there were significant differences in the total raw scores between the clinic and control groups.

In addressing the results to the first question, there were no differences in the prevalence of behavioral problems between speech and/or language impaired children and normal children, as reported by parents and teachers. However, when the boys' data were further analyzed by dividing them into 3 groups, the teachers did report a significantly higher number of behavior problems for the speech and language, and language impaired boys, and parents reported this group to be less skilled in the area of social competence in comparison to the speech impaired boys. The results to the second question showed there were no significant differences in the types of behavior problems between the speech and/or language impaired girls and normal girls as reported by teachers, but parents described the clinic girls as being more hyperactive and having lower school performance. There 
were no significant differences reported for the speech and/or language impaired boys and normal boys, although there was a trend toward significance for the hyperactive behavior problem scale with the clinic boys having the higher number of problems. However, when the boys' data were further analyzed by dividing them into 3 groups, significant differences emerged. The speech and language, and language impaired boys were reported to have significantly lower school performance levels by both the parents and teachers. In addition, the teachers stated they were inattentive, aggressive and had more problems with learning. On the adaptive functioning items of working hard and behaving appropriately, and on the teacher reported behavior problem scale of Externalizing, the speech and language, and language impaired group had significantly more problems than the speech impaired group. 


\title{
A COMPARISON OF BEHAVIORAL PROBLEMS BETWEEN SPEECH AND/OR LANGUAGE IMPAIRED CHILDREN \\ AND NORMAL CHILDREN
}

by

JEANNIE BOTELHO

A thesis submitted in partial fulfillment of the requirements for the degree of

\author{
MASTER OF SCIENCE IN SPEECH COMMUNICATION: \\ with an emphasis in \\ SPEECH-LANGUAGE PATHOLOGY
}

Portland State University

1986 
TO THE OFFICE OF GRADUATE STUDIES AND RESEARCH:

The members of the Committee approve the thesis of Jeannie S. Botelho presented June 11, 1986.

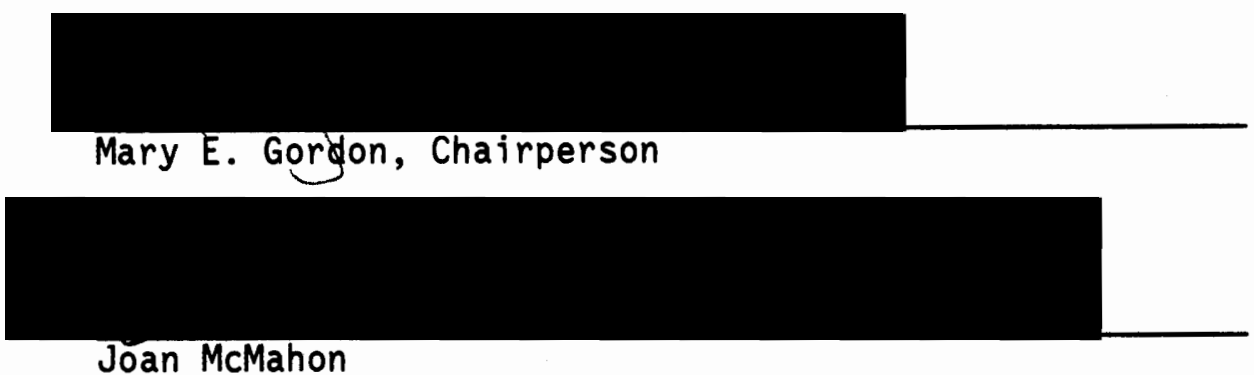

APPROVED:

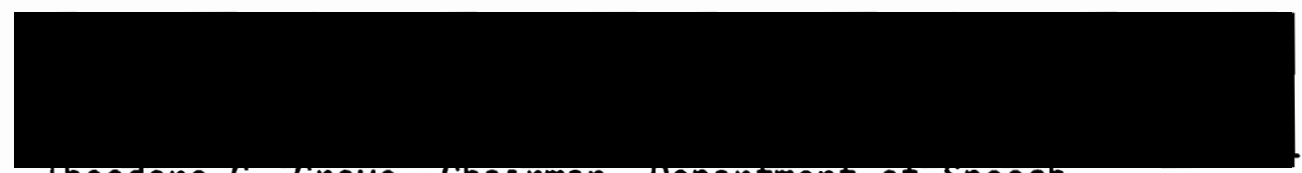

Theodore G. Grove, Chatrman, vepartment or speech

Bernard Ross, Dean of Graduate Studies and Research 


\section{ACKNOWLEDGEMENTS}

This thesis turned out to be quite a group project, so I have many people to thank who made major contributions in helping me complete this seemingly unending endeavor.

A sincere thank you to:

- The teachers, parents and children who participated in this study.

- The members of my thesis committee: Mary Gordon, Joan McMahon and Maxine Thomas.

- Karen Nelson

- Patricia O'Meara

- Connie Emerson

- Gail Buchanan

- Tom Moran

- John Putnam

- Susan Crowel1

- Tom, Priscilla, Megan \& Lauren Andres

- My Family

- JSB 


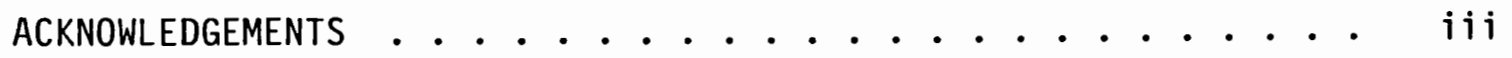

LIST OF TABLES . . . . . . . . . . . . . . . . . . • . v vi

LIST OF FIGURES . . . . . . . . . . . . . . . . . . . . viii

CHAPTER

I INTRODUCTION AND STATEMENT OF PURPOSE $\quad \cdot \ldots$. . . . 1

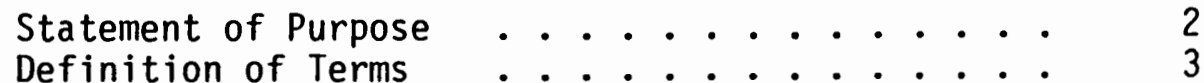

II REVIEW OF THE LITERATURE $\quad$. . . . . . . . . . . . 4

Behavioral Problems in the General Population of

Speech and Language Impaired Children " •.

Comparisons of Behavioral Problems between "Pure"

Speech, Speech and Language, and Language

Disordered Children .............. . . 11

Behavioral Problems in Speech Impaired Children . 15

$\begin{array}{lll}\text { Behavioral Problems in Language Impaired } & & \\ \text { Children } & \text {. . . . . . . . . . . . . . } 18\end{array}$

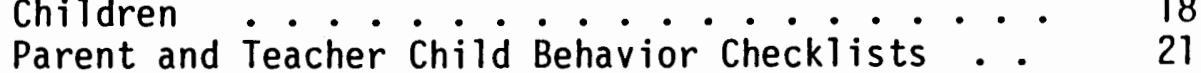

Summary . . . . . . . . . . . . . . 24

III METHODS . . . . . . . . . . . . . . 26

Subjects ................... . . . . 26

Description of Subjects . . . . . . . . 27

Instrumentation ................. 27

Child Behavior Checklist - Parent Report

Form ................... 27

Child Behavior Profile . . . . . . . . 28

Reliability .............. . . 28

Validity ............... . . 28

Child Behavior Checklist - Teacher Report

Form . . . . . . . . . . . . . 29

Child Behavior Profile ........... 29

Reliability ................. 30

Procedures .................. . . 30

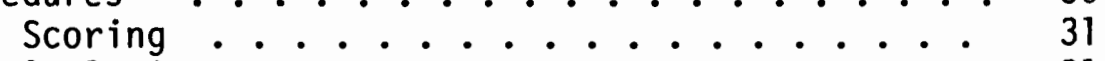

Data Analysis ..................... 31 
IV RESULTS AND DISCUSSION ................. 33

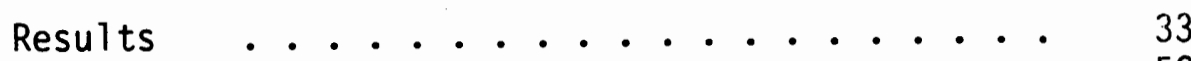

Discussion .. . . . . . . . . . . 52

$\checkmark$ SUMMARY AND IMPLICATIONS ......................... 61

Summary . . . . . . . . . . . . . . 61

Clinical Implications .......... 64

Research Implications .......... 65

SELECTED BIBLIOGRAPHY • . . . . . . . . . . . . . . . . . 67

APPENDICES . . . . . . . . . . . . . . . . . . . . . . 71 


\section{LIST OF TABLES}

TABLE

Page

I Raw scores for the speech and/or language impaired and normal girls on the Child Behavior Profiles: means and standard deviations .......... 34

II Raw scores for the speech and/or language impaired and normal boys on the Child Behavior Profiles: means and standard deviations

III Raw scores for the speech impaired (group 1), the speech and language, and language impaired (group 2), and normal (group 3) boys on the Child Behavior Profiles: means and standard deviations ............ 36

IV Analysis of variance indicating differences between the speech impaired (group 1), the speech and language, and language impaired (group 2), and normal (group 3) boys .38

$\checkmark$ Raw scores for the speech and/or language impaired and normal girls on the parent reported behavior problem and competence scales: means and standard deviations . . 40

VI Raw scores for the speech and/or language impaired and normal girls on the teacher reported behavior problem and adaptive functioning scales: means and standard deviations

VII Raw scores for the speech and/or language impaired and normal boys on the parent reported behavior problem and social competence scales: means and standard deviations.

VIII Raw scores for the speech and/or language impaired and normal boys on the teacher reported behavior problem and adaptive functioning scales: means and standard deviations

IX Analysis of variance indicating differences between the clinic and control girls 
$X$ Raw scores for the speech impaired (group 1), the speech and language, and language impaired (group 2), and normal (group 3 ) boys on the parent reported behavior problem and social competence scales: means and standard deviations

XI Raw scores for the speech impaired (group 1), the speech and language, and language impaired (group 2), and normal (group 3 ) boys on the teacher reported behavior problem and adaptive functioning scales: means and standard deviations

XII Analysis of variance indicating differences between the speech impaired (group 1), the speech and language, and language impaired (group 2), and normal (group 3) boys . . 49 


\section{LIST OF FIGURES}

FIGURE

1. Mean Scores on the Child Behavior Profiles for the three groups of boys .............. 37

2. Parent reported differences between the speech and/or language impaired girls and normal girls ....... . 44

3. Parent reported school performance levels for the 3 groups of boys ................ . 48

4. Mean scores on the teacher reported behavior problem scales for the 3 groups of boys ............ 50

5. Mean scores for the adaptive functioning items for the 3 groups of boys ............... 51 


\section{CHAPTER I}

\section{INTRODUCTION AND STATEMENT OF PURPOSE}

\section{Introduction}

According to Holt (1969), children want to make sense of the world, themselves and other human beings. The primary medium which facilitates this process is the acquisition of a communication system. As Wood (1981) has stated, children need "communication power" in order to function in their family, social groups, classroom and community. Through the use of this communication power, children learn many strategies which help them make sense of their world. During the early developmental stages of speech and language acquisition, children frequently experience some frustration in their attempts to express verbally their needs, wants and ideas to others. For children who are communicatively disordered, these normal frustrations may be greatly intensified as they unsuccessfully attempt to interact with others and fail to form "normal" relationships (Peddicord, 1979). In effect, they are failing to make sense of their world. It is hardly surprising that negative consequences result when children fail to develop effective communication power.

It has been documented in the literature that speech and language disordered children are at risk for behavioral, social and emotional problems (Cantwell and Baker, 1977). In an epidemiological study of the prevalence and type of psychiatric disorders in 100 speech and language delayed children, 53 were diagnosed by psychiatrists as having a 
definable psychiatric disorder (Cantwe11, Baker, and Mattison, 1979). The authors concluded there is a need for speech-language pathologists to evaluate speech and language delayed children for behavioral problems, to enable a multimodal $\mathrm{plan}$ of intervention. They suggested parent and teacher behavior rating scales can provide a systematic assessment procedure.

In the study by Cantwell et al. (1979), the prevalence of psychiatric disorder among speech and language disordered children was found to be more than 50 percent. This is significantly higher than the incidence of 15 percent they used for comparison which was documented in the President's Commission on Mental Health (1978). However, in their research they did not use a control group of "normal" children for direct comparison of the prevalence and type of behavioral problems. If parent and teacher behavior rating scales are a valid procedure of assessing children's behavioral problems, and the prevalence figures are accurate, it is hypothesized that significantly different scores would be found between a control group of "normal" children and a group of speech and/or language impaired children.

\section{Statement of Purpose}

The purpose of this investigation was to compare the prevalence of behavioral problems between speech and/or language impaired children and "normal" children, between the ages of 5-11, as evaluated by parent and teacher behavior rating scales.

The questions this investigation sought to answer were:

1. Is there a significant difference in the prevalence of 
behavioral problems between speech and/or language impaired children and "normal" children as reported by parents and teachers?

2. Is there a significant difference in the types of behavioral problems between speech and/or language impaired children and "normal" children as reported by parents and teachers?

\section{Definition of Terms}

The following operational definitions were used for the purpose of this study:

Speech and/or Language Impaired Subjects: subjects who are diagnosed by their speech-language clinicians as demonstrating any speech and/or language delay and/or disorder considered severe enough to warrant intervention and who are mainstreamed in regular education classrooms.

Behavioral Problem: a problem of behavior, emotions, or relationships sufficiently prolonged and/or severe to cause a disturbance in his/her environment, as perceived and reported by parents and teachers (adapted from Rutter, Tizard, and Whitmore 1970).

Normal Subjects: subjects who are mainstreamed in regular classrooms, with normal speech, language and hearing, as determined by the child's past school records. 
CHAPTER II

REVIEW OF THE LITERATURE

Children with handicaps of all types are at risk for psychiatric disorders (Cantwell and Baker, 1977). Rutter, Tizard and Whitmore (1970) reported that intellectually retarded children have a prevalence rate for psychiatric problems six times that of the general population. Similarly, brain-damaged children have a prevalence rate five times higher, and physically handicapped children whose handicaps do not directly involve the central nervous system have a prevalence rate twice as high (Rutter, Graham and Yule, 1970). It has been suggested language is instrumental in the development of concepts, thought, play, socialization, self-image, humor, memory, reading and education (Baker and Cantwell, 1982b). Since communication plays such a central role in the way humans function within their environment, it seems logical that any impairment associated with the acquisition of speech and language would adversely affect other areas of development. The high prevalence of abnormalities in behavioral, social and emotional development in speech and language disordered children has been reported by many researchers. A selective review of these studies will be presented.

Behavioral Problems in the General Population of

Speech and Language Impaired Children

From their extensive review of the literature, Cantwell and Baker 
(1977) reached a tentative conclusion that when children with communication disorders are considered as a group, they probably do have an increased prevalence of psychiatric disorders. In addition, the types of psychiatric disorders were described as being similar to those of children of the same age in the general population. Thus the communicatively disordered population do not appear to exhibit unique behavioral problems. However, they maintained that these "conclusions" could not be stated with certainty, because of methodological problems. These were described as problems in diagnosing and defining psychiatric disorder, description of the type of speech and/or language retardation, reliability and validity of the instruments to assess both the speech and language and psychiatric disorders, sampling bias and inadequate sampling size, and finally, failure to consider other associated factors in the child, such as mental retardation and brain damage.

In an attempt to overcome some of these methodological problems, Cantwell et al. (1979) conducted a study which included a large number of children, with a variety of speech and language disorders believed to be representative of the general population of speech and language impaired. These children were evaluated systematically by a psychiatrist with regard to presence or absence of psychiatric disorders and a psycholinguist to determine the type of speech and/or language disturbance. In addition, two parent behavior rating scales and two teacher behavior rating scales were used to investigate further the presence of psychiatric disorder. These questionnaires were modified forms of the Conners Parent and Teacher Questionnaires (Conners, 1973) and the Rutter Parent and Teacher Questionnaires (Rutter et al., 1970). The 
subjects were selected from 239 consecutive cases referred to a community speech and hearing clinic in Los Angeles.

They reported the data for the first 100 preschool through middle school aged subjects seen in the study. There were complicating factors reported for twelve of these children: 5 were mentally retarded, 4 suffered from some hearing impairment, 1 came from a bilingual background, and 2 were austistic. The psychiatric evaluations revealed that 53 of the 100 children received at least one psychiatric diagnosis, the most common one being Attentional Deficit Disorder, which occurred in 19 children. The central features of this disorder are developmentally inappropriate short attention span and poor concentration. The second most common diagnosis was Oppositional Disorder, which was present in 13 children. This disorder is described as being a pervasive opposition to all in authority, continuous argumentativeness and unwillingness to respond to reasonable persuasion. Twelve children were found to have various anxiety disorders: 7 with Shyness Disorder, 2 with Overanxious Disorder, and 3 with Separation Anxiety Disorder. Four children had conduct disorders characterized by repetitive and persistent patterns of antisocial behavior as it violates the rights of others, 1 had a chronic depressive disorder, and 1 had a stereotyped movement disorder. These researchers concluded that a significant number of the speech and language disordered children had specific types of psychiatric problems.

In a later publication, Mattison, Cantwell and Baker (1980) described the behavioral symptoms reported by the modified Connors (1969) and Rutter (1970a) parent and teacher questionnaires. The behaviors that were rated as occurring the most frequently (e.g., by 
45 percent or more of the parents) were: Attentional-Motor Items easily frustrated, excitable, impulsive, restlessness, short attention, easily distracted, and tantrums; Conduct Items - disobeys at home; Health Items - night-mares, problems getting to sleep and stomachaches; Developmental and Language Items - hard to understand; Mood Items - angry or irritable; Emotional Items - overly sensitive and blames others; Relationship Items - shy, fights with siblings, solitary and afraid of new people.

For the teacher questionnaire, the behaviors rated as occurring the most frequently (e.g., by 39 percent or more of the teachers) were: Attentional-Motor Items - poor attention, fidgety, restlessness and easily frustrated; Development and Language Items - hard to understand, limited language and uncoordinated; Relationship Items - shy, not a.leader, disturbing, solitary, stubborn and submissive. It was found that parents and teachers rated the same items quite similarly, except parents rated excitability, temper tantrum, easily frustrated, complaints of aches and thumb sucking as occurring more often. The teachers reported tics, fighting and disobeying at school more frequently. The authors concluded the parents and teachers essentially agreed with an examining psychiatrist, particularly concerning the attentional-motor and relationship items, and that children with speech and language disorders often do have related behavioral problems. However, they did not compare their results with normative data. Since most children exhibit behavior "problems" to some extent, it cannot be determined if these data reflect significant behavioral differences between a speech-language impaired population and their normal peers. 
In a further study Cantwell and Baker (1980) reported results of the prevalence and type of psychiatric and behavioral disorders seen in 196 preschool through middle school aged speech and language disordered children. Similar results were found in that 53 percent of these children received a psychiatric diagnosis. There were 51 diagnoses in the area of behavior disorders and 23 in the area of anxiety disorders. Seven children were mentally retarded, 2 were autistic, and 3 had a chronic depressive disorder. They did not use a control group of children from the "normal" population, but suggested the prevalence rate of 53 percent was significant in comparison to the percentages in the President's Commission of Mental Health (1978) which was reported to be 5 to 10 percent in rural populations and 10 to 15 percent in urban populations.

In taking a critical look at the studies designed by Cantwell et al. (1979), Mattison et al. (1980) and Cantwell and Baker (1980) with the purpose of evaluating any methodological problems, it seems that 3 areas could be explored further. First, with regard to sampling bias, they drew their subjects solely from referrals to one community speech and hearing clinic. There is a possibility that this setting reflects more severe problems than would otherwise be characteristic of a "general" speech and language impaired population. Secondly, their speech and language impaired population did include children with other handicapping conditions, such as mental retardation and autism. The difficulty then is deciding what is related to the behavioral problems, the mental retardation/autism or the speech and language impairment. It would be useful to collect data on 
subjects whose primary handicapping condition was that of speech and/or language impairment and who were selected from a public school setting. Finally, inclusion of a control group of "normals" could provide further data to substantiate the claims that the speech and language disordered population do in fact have a higher prevalence of certain types of behavioral problems.

Other researchers have supported the association of behavioral problems with speech and language impaired children. In a study which described the prevalence of behavior problems found in a sample of 418 preschool children in North London, an association was found between delayed speech and language development and behavior problems (Jenkins, Bax, and Hart, 1980). Beckey (1942) examined factors related to delayed speech development. Through observation of the children and review of teachers' record, Beckey concluded children with delayed speech do not want attention. He reported these children tend to play alone and cry easily. Temper tantrum, thumb sucking and enuresis were found not to be significant factors. It is difficult to compare Beckey's (1942) results with Cantwell and Baker (1980) as delayed speech was not defined in Beckey's study. However, some of the results differed in that Cantwell and Baker reported temper tantrums and thumb sucking to be frequent behavioral symptoms.

Two studies have investigated the incidence of speech disorders in children referred to child guidance clinics. Wylie, Franchack, and McWilliams (1965) identified 45 (or 15 percent) out of a total 292 children who exhibited "defective speech." This included 27 percent with articulation problems, 24 percent with delayed speech, 20 percent were 
stutterers, and 29 percent had combined disorders. There were 17 symptoms reported more frequently for children exhibiting defective speech than for children with normal speech. However, only five of these were statistically significant: soiling, thumbsucking, wetting, hyperactivity and involuntary movements. One symptom, fighting with parents, was significantly more frequent in the children without speech problems. The speech defective group was significantly younger than the remaining group of referred children. The speech defective group age range was from 2 to 16 years, the mean age was 8; the mode, 6. For the remaining children, the age range was 3 to 17 years, the mean was 10 and the mode, 9 . It is interesting to note some of the behaviors which were significantly more frequent in the speech defective group, could be related to their younger age, rather than representing an association with their speech and/or language problems.

In the second study, Chess and Rosenberg (1974) found 139 (29 percent) of 563 school aged children referred to a private child guidance practice, had some kind of speech and/or language difficulty at the time of initial assessment. A similar finding was reported in that the speech and language disordered group were referred at an earlier age than the other children. Chess and Rosenberg postulated that speech disorders may provide the clinician with an early indication of psychiatric problems. The behavior problems described in this group included: tantrums, disruptive behavior, difficulties in relationships with peers, discipline problems, enuresis, separation anxiety, withdrawn behavior, hypochondriasis, and extreme sulleness. 
Parents reported behavioral problems in 99 out of the 139 cases, so that 64 percent of the children had difficulty of sufficient degree as to be noticed by parents. In drawing conclusions from both of these studies, the populations that were investigated should be taken into account. Children referred to child guidance clinics may reflect more severe problems than the "general" population of speech and language impaired children.

Using Quay's Behavior Problem Checklist, Lindholm and Touliatos (1979) compared how teachers rated kindergarten through eighth grade children from regular classes with children receiving speech treatment. Overall, it was found that children in regular classes had fewer behavior problems than the children diagnosed as receiving speech treatment. The differences were signifcant for Personality Problems and Psychotic Signs $(p=.05)$. They were trending towards significance for Inadequacy-Immaturity $(p=.10)$, but were not for Conduct Problems and Socialized Delinquency. The group receiving speech treatment was more likely to have difficulties such as being anxious and withdrawn or being passive and having a short attention span. They added that the difference in Psychotic Signs was probably related to speech problems rather than to real signs of psychosis, as two items referred to speech (incoherent and repetitive). In this study, no information was given regarding the type of speech and language problems to describe the group of children who were receiving speech intervention.

\section{Comparisons of Behavioral Problems between "Pure" Speech,}

Speech and Language, and Language Disordered Children 
Baker, Cantwell and Mattison (1980) compared children with "pure" speech disorders to children with disorders of both speech and language. Their purpose was to determine if the frequency, type and severity of behavioral problems differed between the two groups. To assess this, they used parent and teacher questionnaires as cited in a previous study (Cantwell et al., 1979). Subjects were 99 preschool through middle school aged children referred to a community speech and hearing clinic. Mean scores were computed for each behavioral symptom and group comparisons were made on individual symptoms and on combinations of some symptoms.

Results indicated that in some areas the speech and language disordered group had increased frequency and severity of behavior problems, and different types of behavioral abnormalities to the "pure" speech group. Teachers of the speech and language disordered group reported a mean number of 15 problems, whereas for the "pure" speech group, the mean number was 7 . This result was statistically significant at the .003 level. This difference for mean number of problems was not reported by parents. However, there were some problems that were rated as being severe for the speech and language disordered group but not for the pure speech group. These were: immaturity, restlessness, short attention span, excitability, tantrums, constant climbing and solitary behavior. Problems that were more severe for the pure speech group were stomachaches, nightmares and fights with siblings. Problems that were common to both groups were generally reported to be more severe by the parents of the speech and language group. Teachers rated the speech and language group as 
significantly more of an overall problem, and significantly more of a problem in academic achievement, overall behavior, and attitude to authority.

In comparing combinations of some symptoms, hyperactive behaviors (e.g., restlessness, short attention span, impulsiveness, fidgety behavior) and developmental phenomena (e.g., wetting pants or bed, clinging to parents and crying easily) were the areas that distinguished the 2 groups, with these problems being more common in the speech and language disordered group. Conduct disorders, relationship and emotional symptoms did not differentiate the two groups. The authors concluded speech-language pathologists need to be aware that behavioral problems are common among speech and/or language disordered children, in particular those children who have problems in both speech and language.

Baker and Cantwell (1982c) extended the analysis of their previous study to include 291 subjects of 3 groups: those with speech disorders, those with both speech and language disorders, and those with language disorders only. The purpose was to further investigate if children with certain types of speech and language disorders are more prone to psychiatric disturbance and to psychiatric disturbances of specific types. The purely speech disordered group had impairments of articulation, or a voice or rhythm disorder, but had language skills appropriate to their age levels. The speech and language disordered group had a speech disorder and a problem with language comprehension, expression or processing skills, functioning at least 6 months below chronological age. The purely language disordered group 
had speech within normal limits, but either a language comprehension, expression or processing disorder as defined above.

Almost half of the 291 subjects had a definable psychiatric diagnosis, although the prevalence rate varied considerably among the 3 diagnostic groups; 29 percent of the speech group, 45 percent of the speech and language disordered group, and 95 percent of the language disordered children were psychiatrically ill. These clinical psychiatric diagnoses did not include developmental disorders (e.g., enuresis, encopresis, specific developmental reading disorder, coordination disorders, learning disabilities and mental retardation.) However, it was noted for the developmental disorders, the prevalence followed a similar pattern. In comparing the types of psychiatric disorders, it was found that the distribution of emotional disorders (separation-anxiety, avoidant, overanxious and adjustment disorders) and behavioral disorders (attention-deficit, conduct and oppositional disorders) were significantly different in the 3 groups of children. Emotional disorders affected 21 percent of the speech group, 30 percent of the speech and language group and 53 percent of the pure language group. Behavior problems were more common in the latter two groups. Their findings indicated their subjects did not form a homogeneous group with regard to the prevalence and type of psychiatric illness. Those children who were most seriously "at risk" were those with a disorder of language comprehension, expression or processing, but with speech being within normal limits. Thus the language disorder appeared to be the most significant variable determining the occurrence of a psychiatric problem. Other studies have supported this finding. Baker and Cantwell (1982a) 
reported data on 76 children with a pure speech disorder and 104 language impaired children. A diagnosable psychiatric illness was more than twice as prevalent in the language disordered group than in the pure speech group. In the study which investigated depression in 600 children with speech, language and learning disorders, 4 percent had an affective disorder diagnosis (Cantwell and Baker, 1983). The depressed children tended to be older, were more likely to have a "pure" language disorder and were more frequently learning disabled.

\section{Behavioral Problems in Speech Impaired Children}

Weiss, Lillywhite and Gordon (1980) discussed the social-emotional, occupational and interpersonal effects of articulation disorders. They suggested articulation disorders could have serious repercusions on an individual's social-emotional well-being, occupation and interpersonal relations. An individual with an articulation disorder may potentially be exposed to unfavorable comments, teasing, ostracism, exclusion and labeling which could negatively affect the individual's sense of selfworth leading to feelings of inadequacy.

Behavioral problems in children with articulation disorders have been reported. Fitzsimons (1958) compared 70 first grade children with normal speech and 70 first grade children with nonorganic articulatory problems. She found the conduct and habit disorders of destructiveness, eating problems, fears, jealousy, nervousness, disobedience, showing off, shyness, temper tantrums and thumb sucking were significantly more common in the speech handicapped group. Solomon (1961) also investigated the possible relationship between functional 
articulation disorders in children and personality and behavior patterns. He examined 9 selected behaviors in a group of children with functional articulation disorders and a group of normal speaking peers. The behaviors were: eating behavior, sleeping, toilet training, fears and anxieties, comfort patterns, tension, aggression, dependency and peer relations. Data were collected by using an open-ended questionnaire-type interview with the mothers. The protocols were then rated by 2 judges to obtain quantitative and qualitative information. Mothers reported significantly higher problems with sleeping behavior, fears and anxieties, tension and peer relationships in the children with articulation problems. The control group of normal speaking children did exhibit some behavior problems, but never to a significantly greater extent than the articulation group.

Trapp and Evan (1960) compared performances on the Wechsler digitsymbol subtest between children 8 to 10 years of age with "mild articulatory defects," children with "more severe defects" and a control group of normal children. This nonverbal test was selected because of its recognized sensitivity to anxiety level. Results show the children with mild articulation defects perform significantly higher on the digit-symbol subtest than the other two groups. Interestingly enough, there was not a significant difference between the control group and the children with severe articulation defects. The significant differences occurred between the mild and severe articulation groups, and the mild articulation and control groups, but when the two clinic groups were combined and then compared with the control group, results were not significant. This indicates a need to 
compare problems according to severity levels, so as not to mask out any potential differences.

Wylie et al. (1965) found that of 292 children who were referred to a child guidance clinic, 45 or 15 percent exhibited "defective speech." of this number 12 or 27 percent had articulation problems. Their symptoms included the following: poor school achievement (83\%), poor attention (58\%), fighting with parents (58\%), sensitive to criticism $(50 \%)$, tantrums $(50 \%)$, fighting with peers $(42 \%)$, feeling inferior $(42 \%)$, friendless $(42 \%)$ and shy $(42 \%)$. The percentages in parentheses indicate the frequency for each symptom.

Goodstein's (1958) survey of the literature on personality and functional speech disorders, reported that in twelve studies investigating the association of personality maladjustment and functional articulatory disorders, only 5 found personality and adjustment problems. Spriestersbach (1956) reviewed some of these same studies and found that of nine studies there was a 5 to 4 count in favor of "maladjustment." He suggested the data were not conclusive enough on which to base any kind of generalization. Like Trapp and Evan (1960), he pointed out the need to focus on speakers with more severe articulatory problems, rather than the general population of individuals with articulatory problems, so as not to mask out any potential differences that may exist.

In looking at the association of personality problems with voice disorders or stuttering, Goodstein's (1958) survey of the literature did not find empirical evidence to support any association between voice disorders and personality type, and stuttering and personality type. Muma, Laeder and Webb's (1968) study reported similar results, in that 
individuals with voice disorders did not differ significantly in their personality characteristics and peer evaluations in comparisons to a controlled group of normals. Sheehan's (1962) evaluation of studies which investigated differences between stutterers and nonstutterers revealed no significant differences in specific personality types or disorders. His findings concurred with those of Goodstein (1958).

\section{Behavioral Problems in Language Impaired Children}

Wiig and Semel (1976) described the implications of language disabilities in children and adolescents on academic achievement and interpersonal interaction. Many of the potential negative consequences included academic and social failure, social rejection and development of nonadaptive emotional reactions. Research has essentially reported an association between language delay/disorder with behavior problems.

In an epidemiological study of the language and behavior of a random sample of 705 3-year old children, 24 (3.1\%) children with language delay were identified using a measure of the child's expressive vocabulary and expressive syntax and 101 (14.3\%) were found with behavior problems as identified by the investigators' Behavior Screening Questionnaire (Stevenson and Richman, 1978). A follow-up evaluation of the 2 groups found in the children with expressive language delay (defined as a language age less than 30 months), 13 (59.1\%) had behavioral problems. The difference between the prevalence of behavior problems in the language delayed population and the general population $(14.3 \%)$ was highly significant $(\mathcal{P}<.001)$. Similar$1 y$, of the 101 children who were initially identified as having behav- 
ior problems, 12.9 percent of them had expressive language delay, in comparison to 3.1 percent of the total population. This again was highly significant $(p<.001)$. In comparing the types of problem behaviors between children with language delay and children with behavior problems, there were few differences, except one child with language delay was severely retarded with autistic characteristics. However, problems in social relationships (dependency, relationships with siblings, relationships with peers) were significantly more frequent in the language delay group than in the total population, as were problems with parental control, unhappy moods, poor appetite, overactivity and concentration. In addition, behavior problems were significantly more severe in the language delayed population. Wylie et al. (1965) found in a child guidance clinic population, 15 percent exhibited "defective speech." of this group, 24 percent had delayed speech only, in that their articulation was within normal limits, but their language development was delayed. The patterns of behavior symptoms included: fighting with parents $(82 \%)$, tantrums $(73 \%)$, wetting $(55 \%)$, hyperactivity $(55 \%)$, poor attention $(55 \%)$, and soiling (45\%).

Both Ingram (1959) and Weiner (1968) reviewed groups of school aged children currently receiving language instruction from speechlanguage pathologists. Ingram found within his own caseload of 80 children with developmental language disorders, 10 were also undergoing psychiatric treatment. Weiner reported speech clinicians' caseloads typically had sizeable numbers of severely emotionally disturbed children. Many of these children presented with inadequate language development. 
In Wing's (1969) study of children with various handicaps, she reported a number of social abnormalities in children with developmental language disorder. The main behavioral problems of these children were awkwardness in social situations, lack of normal play behavior, and socially embarassing behaviors such as tantrums.

Baker and Cantwell (1982c) cited the research of Caceres (1971) who examined the case histories of 25 language retarded children between the ages of 3 to 13. From the parental reports and Caceres' own evaluations, it was found 84 percent of the children had some type of psychiatric problem. Fifty-six percent of the children were labeled as hyperactive, aggressive or destructive and 28 percent were labeled as being timid or inhibited.

Griffith (1969) conducted a follow-up study of 49 language disordered children. All of the children had attended a special education school designed specifically for language handicapped children. Each had attended a minimum of 2 semesters and had left the school 12 months or more before the study started. Social and emotional status was one area they investigated. Of the 49 subjects, 12 were rated as having poor or very poor social development, and 22 as having poor or very poor emotional adjustment. The highest percentage of problems were found in those children who had entered secondary school, with most of the problems being manifested in the home situation rather than at school. Similarly, Baker and Cantwell (1984) conducted a follow-up study of speech and/or language impaired children who were initially assessed as having concommitant behavioral problems. Evaluations 4 years later showed children with speech problems to have 
fewer psychological problems, but children with language disorders presented with an increase of psychological problems; furthermore these problems were of a more severe nature even though their speech and language ability had improved. Language seemed to be a significant variable associated with behavioral problems.

\section{Parent and Teacher Child Behavior Checklist}

In reviewing these studies it can be seen that a variety of evaluation methods were used to investigate behavioral problems in speech and/or language impaired children. Interviewing a parent using a behavior checklist as part of the evaluation was commonly used although information was invariably lacking regarding selection of the questions, normative data, validity and reliability, except for the study by Lindholm and Touliatos (1979), who used Quay's Behavior Checklist, and the collective studies by Baker, Cantwell and Mattison.

The parent and teacher child behavior checklists (CBCLs) used in this study were developed by Achenbach and Edelbrock (1983). The child behavior checklists have extensive reliability, validity and normative data. They were designed to record in a standardized format the behavior problems and competencies of children aged 4 through 16 . The behavior problems descriptions were compiled from a survey of existing clinical and research literature, and consultation with clinical and developmental psychologists, child psychiatrists, and psychiatric social workers (Achenbach and Edelbrock, 1983). Achenbach and Edelbrock chose to use parent reports as the focus of an assessment approach as parents are the most universally available informants with 
the greatest knowledge of a child across time and situations.

Furthermore, even though their perceptions of their child's behavior may be biased, they are central in determining what will be done about it, and they are usually involved in both the evaluation and treatment of their child. They also developed a teacher report form of the CBCL as teachers are usually an important influence in the child's life, and behavioral concerns not evident to parents may be of concern to teachers. Other supplementary assessments have been developed, including a Direct Observation Form of the child and a Youth Self Report Form for children aged 11 to 18, although neither of these were used in this study.

The parent report form of the $\mathrm{CBCL}$ contains 20 social competence items and 118 behavior problem items (Appendix A). These items are scored on a Child Behavior Profile. The social competence items are scored on 3 scales labeled Activities, Social and School, which were formed on the basis of their content. The behavior problem items are scored on scales which were developed by performing principal component analyses of the CBCLs filled out by the parents of children referred for outpatient mental health services (Achenbach and Edelbrock, 1983). Clinically-referred children were used so as to identify syndromes of behavior problems. The scales were developed for children of each sex at ages 4 to 5,6 to 11 , and 12 to 16, to allow for age and sex differences in the prevalence and patterning of behavior problems. Thus there are different syndromes or behavior problem scales for each sex at each age level. For example, see Child Behavior Profile for boys age 6 to 11 (Appendix B) and Child Behavior Profile for girls age 6 to 11 (Appendix 
C). Labels were used to identify each scale to summarize the behavior problem items. In addition, second-order factor analyses of these behavior problem scales showed that there were 2 broad-band groups for both sexes in each of the age groups. One broad-band grouping comprised problems within the self (labeled Internalizing), and the second comprised problems of conflict with the outside world (labeled Externalizing). On each Child Behavior Profile the behavior problem scales are arranged according to their loadings on the Internalizing and Externalizing factors. The Internalizing behavior problem scales are arranged on the left side starting with the highest and progressing to the lowest loading. The Externalizing behavior problem scales are arranged on the right side starting in the middle with the lowest factor loadings progressing to the highest. When one scale had moderate loadings for both the Internalizing and Externalizing factors, it was not counted as part of either one. Once the factor based scales were constructed using a clinical population, normative data were compiled from parents of randomly selected children who had not received mental health services for at least the preceding year. Normalized $T$ scores were then derived from the raw scores on each behavior problem and social competence scale.

The teacher report form of the $\mathrm{CBCL}$ (Appendix D) obtains ratings of academic performance, general adaptive characteristics, and behavior problems items pertinent to the school setting. These ratings are then scored on a Child Behavior Profile (Appendix $E$ and $F$ ) which was constructed in a similar way to the parent form of the Child Behavior Profile. 
Both the parent and teacher report forms of the CBCL developed by Achenbach and Edelbrock provide a standardized way to obtain extensive information regarding a child's behavior. Normative data are available and there are reliability and validity studies reported (Achenbach and Edelbrock, 1983). Furthermore, there is a definite similarity between these parent and teacher report forms and those used in the research by Baker, Cantwell and Mattison, as most of the behavior problem questions are identical. Thus, some comparisons could be drawn.

\section{Summary}

A communication system is central to the way in which human beings develop, learn and interact. If a child is unable to communicate effectively, then he or she will encounter many difficulties in his or her environment. From the selection of studies reviewed, it has been shown speech and/or language impaired children are at risk for behavioral problems. Many of the studies interviewed parents using a behavior checklist to obtain information regarding the children's behavior, al though it was often unclear how the checklist was developed, and whether it is a reliable and valid method to use. Consequently, many of the behavior problems reported may be questionable. However, the collective studies done by Baker, Cantwell and Mattison used quite extensive and thorough procedures to obtain information regarding their subjects' behavior. They consistently reported a prevalence rate of at least 50 percent for psychiatric diagnoses for the speech and/or language impaired sample. However, they included children with other handicapping conditions, they did not use a control group of "normal" children for 
comparison, and their subjects were drawn from a community speech and hearing clinic which may not be representative of a speech and/or language impaired population. It would be beneficial to obtain behavioral data about children whose primary handicapping condition is that of speech and/or language impairment, who are selected from a public school setting, and then compare them to their "norma1" peers. This study attempted to do this using the standardized Parent and Teacher Report Forms of the Child Behavior Checklists designed by Achenbach and Edelbrock (1983). 
CHAPTER III

METHODS AND PROCEDURES

\section{Subjects}

Thirty-eight children between the ages of 5 and 11 years were selected from two elementary schools within the Centennial School District, Portland, Oregon. The subjects included 19 speech and/or language impaired children and 19 normal children.

The two groups were selected using the following criteria:

1) Subjects in the speech and language impaired group were diagnosed by the school speech-language pathologist as having an impairment severe enough to warrant intervention. These subjects were selected from the speech-language pathologist's current caseload and they were all mainstreamed in regular education classrooms.

2) Subjects in the normal group were selected from regular education classrooms and had normal speech, hearing and language as verified by the child's school records, parent and teacher report.

3) All subjects had signed parent and teacher permission forms (Appendices $G$ and $H$ ) to participate in the study. In addition, all subjects over the age of 7 had signed student permission forms giving their consent. 


\section{Description of Subjects}

Chronological age and sex of the 38 subjects who participated in the study were as follows: the speech and/or language impaired subjects included 14 boys with a mean age of 7 years, 6 months, and 5 girls with a mean age of 9 years, 5 months. The control group of "normal" subjects included 14 boys with a mean age of 7 years, 5 months, and 5 girls with a mean age of 9 years, 5 months. The speech and/or language impairment of the experimental group of boys was as follows: 3 with a voice disorder, 3 with an articulation disorder, 3 with speech (articulation) and language impairment, and 5 with a language impairment only. Of the girls, 2 had an articulation disorder, 2 a speech (articulation) and language impairment, and 1 with a language impairment only.

\section{Instrumentation}

The parent and teacher behavior checklists used in this study were developed by Achenbach and Edelbrock (1983).

\section{Child Behavior Checklist (CBCL) - Parent Report Form}

The CBCL (Appendix A) contains 20 social competence and 118 behavior problem items. It can be self-administered or administered by an interviewer. The $\mathrm{CBCL}$ instructs the parent or parent-surrogate to base ratings on the previous six months of the child's behavior. For the social competence items, parents are requested to rate their child in comparison to other children of the same age. On the behavior problem items, the instructions are to circle the items that best describes their child, the choices being: $0=$ not true, $1=$ somewhat or sometimes true, 
and 2 = very true or often true. The $C B C L$ is scored on the social competence and behavior problem scales of the child behavior profile.

\section{Child Behavior Profile}

The child behavior profile (Appendices B and C) consists of scales constructed from analyses of parents' ratings of 2,300 clinically referred children and normed on 1,300 non-referred children. Normalized T scores are assigned to the 3 social competence scales, the behavior problem scales, Internalizing and Externalizing scales and the total behavior problem score. They are shown to the right of the profile and percentiles are shown to the left. Profiles are standardized for each sex in the age ranges of 4 to 5,6 to 11 , and 12 to 16 years. The child behavior profiles for boys age 6 to 11 and girls age 6 to 11 were used for the purpose of this study.

\section{Reliability}

Data have been reported in the manual showing good reliability of this instrument (Achenbach \& Edelbrock, 1983). Test-retest reliability, inter-rater agreement and longer term stability were assessed (see Appendix I).

Validity

Content validity studies showed that clinically referred children received significantly higher scores $(p<.005)$ than nonreferred children on 116 of the 118 behavior items; on all of the 20 social competence items, the clinically referred children received significantly lower scores $(p<.01)$. Construct validity was assessed by comparing the $C B C L$ with the Conners Parent Questionnaire (1973) and the Quay-Pearson (1983) 
revised behavior checklist. See Appendix $J$ for data.

\section{Child Behavior Checklist - Teacher Report Form}

The CBCL - Teacher Report Form (TRF) is a 4-page questionnaire to be completed by teachers or teacher aides (Appendix D). It was designed to obtain teachers' ratings on many of the same problems that parents rate, but omits the items that teachers would not be able to rate and includes additional items related to behavior in school. Current performances in academic subjects are rated on a 5-point scale ranging from 1 (far below grade level) to 5 (far above grade level). There are 4 questions regarding adaptive behavioral functioning, and space available for teachers to report achievement test scores, IQ, readiness or aptitude scores, as well as opportunity for them to make their own comments about the student's work, behavior and potential. The rating scale used for the behavior problem items is the same as the one used for the parent report form, except teachers are instructed to describe the child's behavior as it is now or has been during the past 2 months.

\section{Child Behavior Profile}

The Child Behavior Profiles for the TRFs (Appendices $E$ and F) were constructed in a similar way as the profiles for the parent report forms. The profiles have been standardized for each sex ages 6 to 11 and 12 to 16 using teachers' ratings on 1,700 referred and 1,100 non-referred children. The profiles provide $T$ scores for school performance, the general adaptive characteristics, the behavior problem scales, Internalizing, Externalizing, and total behavior problem score. 
Reliability

One week test-retest reliability for school performance was .93; for total adaptive function score .86, and averaged .89 for the behavior problem scales for the boys in the 6 to 11 age group (Edelbrock and Achenbach, 1984).

\section{Procedures}

Letters were sent home to parents of children who were currently receiving speech-language services in the public schools and to parents of children in regular education classes grades $k-5$. Students with returned signed permission forms were then screened for inclusion in this study. In the final selection of the experimental and control group, the subjects were matched for age, sex and occupational status of a parent (U.S. Department of Labor, 1977).

This investigator then met with the mother or father of the students meeting criteria to explain the nature and the purpose of the questionnaire. It was described in terms of being a checklist to obtain information about a child's behavior as the parent sees it. In addition, the parents were informed it was designed for a wide variety of children with a range of behavior problems, so that many of the behavior items would not seem applicable to their child. The interviews were conducted at either the parent's home or the school where their child attended. Each parent was given the choice of filling out the behavior checklist themselves, or having this investigator read it to them. The interviews took 20 to 40 minutes depending on whether the parent filled out the checklist themselves. If this interviewer 
read the questions to the parent, then the interview lasted longer.

The classroom teacher of each child was given the teacher report form of the CBCL to be filled out. Twelve teachers participated in this study. The checklists were given to each teacher to be completed on their own time. This investigator was not present but was available to answer any questions.

\section{Scoring}

The CBCL's were scored on the Child Behavior Profiles according to the manual instruction guidelines (Achenbach and Edelbrock, 1983). The appropriate profile for the age and sex of the child was used.

\section{Data Analysis}

On the Child Behavior Profile for the parent report form raw scores were computed for the social competence scales, the behavior problem scales, the Internalizing and Externalizing scales, number of items, and total behavior problem score. Similarly, for the TRFs, raw scores were computed for school performance, the adaptive functioning items, the behavior problem scales, the Internalizing and Externalizing scales, number of items and total behavior problem score. Raw scores were analyzed instead of the assigned $T$ scores, to enable differentiation of low scores within the normal range. This allows for assessment of differences that fall within the normal range (Achenbach and Edelbrock, 1983). The data for the boys and girls were analyzed separately, as the raw scores were computed on different Child Behavior Profiles. Further analyses were completed on the boys only by dividing them into three groups: speech impaired only; a 
combined speech and language, and language only impaired; and the control group. This comparison could not be completed for the girls due to the small number of subjects. Analysis of Variance (Anova) and a Tukey post hoc analysis were used to determine whether there were significant differences in the total raw scores between the experimental and control groups. 
CHAPTER IV

RESULTS AND DISCUSSION

\section{Results}

The purpose of this study was to compare the prevalence and types of behavior problems between speech and/or language impaired children and normal children as reported by parents and teachers. Information regarding the 38 subjects' behavior was obtained by using the parent and teacher reported child behavior checklists developed by Achenbach and Edelbrock (1983).

The first question posed was: Is there a significant difference in the prevalence of behavioral problems between speech and/or language impaired children and normal children, as reported by their parents and teachers? To address this question, the raw scores for the total social competence score (parent reported), the total adaptive functioning score (teacher reported), and the total number of behavior problem items and total behavior problem scores for both the parent and teacher report forms were analyzed. Each group's raw score means and standard deviations were computed and are presented in Table I for the girls and Table II for the boys. Analysis of variance (Anova) was used to compare the speech and language impaired children with the normal children to determine if there were any significant differences. 
TABLE I

RAW SCORES FOR THE SPEECH AND/OR LANGUAGE IMPAIRED AND NORMAL GIRLS ON THE CHILD BEHAVIOR PROFILES: MEANS AND STANDARD DEVIATIONS

\begin{tabular}{|c|c|c|c|c|c|c|c|}
\hline \multirow{2}{*}{$\begin{array}{l}\text { Variable } \\
\text { Social Competence }\end{array}$} & \multirow{2}{*}{$\frac{\mathrm{CBCL}}{\text { Parent }}$} & \multicolumn{3}{|c|}{$\begin{array}{l}\text { Clinic Girls } \\
N \text { Mean SD }\end{array}$} & \multicolumn{3}{|c|}{$\begin{array}{l}\text { Normal Girls } \\
\mathrm{N} \text { Mean SD }\end{array}$} \\
\hline & & 5 & 18.20 & 3.58 & 5 & 22.20 & 3.54 \\
\hline $\begin{array}{l}\text { \# Behavior Problem } \\
\text { Items }\end{array}$ & Parent & 5 & 25.20 & 14.56 & 5 & 18.40 & 9.01 \\
\hline $\begin{array}{l}\text { Total Behavior } \\
\text { Problem Score }\end{array}$ & Parent & 5 & 32.60 & 21.82 & 5 & 20.00 & 8.63 \\
\hline Adaptive Functioning & Teacher & 5 & 16.80 & 5.35 & 5 & 20.60 & 3.28 \\
\hline $\begin{array}{l}\text { \# Behavior Problem } \\
\text { Items }\end{array}$ & Teacher & 5 & 11.20 & 9.14 & 5 & 5.40 & 3.28 \\
\hline $\begin{array}{l}\text { Total Behavior } \\
\text { Problem Score }\end{array}$ & Teacher & 5 & 14.40 & 13.12 & 5 & 5.40 & 3.28 \\
\hline
\end{tabular}

TABLE II

RAW SCORES FOR THE SPEECH AND/OR LANGUAGE IMPAIRED AND NORMAL BOYS ON THE CHILD BEHAVIOR PROFILES: MEANS AND STANDARD DEVIATIONS

\begin{tabular}{|c|c|c|c|c|c|c|c|}
\hline \multirow{3}{*}{$\begin{array}{l}\text { Variable } \\
\text { Social Competence }\end{array}$} & \multirow{3}{*}{$\frac{\mathrm{CBCL}}{\text { Parent }}$} & \multicolumn{3}{|c|}{ Clinic Boys } & \multicolumn{3}{|c|}{ Normal Boys } \\
\hline & & $\mathbf{N}$ & Mean & SD & $N$ & Mean & SD \\
\hline & & 12 & 17.91 & 3.30 & 12 & 18.54 & 2.52 \\
\hline $\begin{array}{l}\text { \# Behavior Problem } \\
\text { I tems }\end{array}$ & Parent & 14 & 30.07 & 13.63 & 14 & 27.71 & 15.38 \\
\hline $\begin{array}{l}\text { Total Behavior } \\
\text { Problem Score }\end{array}$ & Parent & 14 & 34.71 & 16.25 & 14 & 30.92 & 19.26 \\
\hline Adaptive Functioning & Teacher & 14 & 15.42 & 7.12 & 14 & 17.71 & 3.68 \\
\hline $\begin{array}{l}\text { \# Behavior Problem } \\
\text { Items }\end{array}$ & Teacher & 14 & 16.35 & 16.43 & 14 & 13.21 & 9.09 \\
\hline $\begin{array}{l}\text { Total Behavior } \\
\text { Problem Score }\end{array}$ & Teacher & 14 & 22.00 & 24.87 & 14 & 15.42 & 12.31 \\
\hline
\end{tabular}


The analyses revealed there were no significant differences in the prevalence of behavior problems between the two groups as reported by parents and teachers. The speech and language impaired children as one group did not have an increased prevalence of behavioral problems in comparison to the control group of normal children. However, when the boys' data were further analyzed by dividing them into the 3 groups of speech impaired (Group 1); combining the speech and language impaired with language impaired (Group 2); and normal (Group 3), significant differences emerged. Each group's raw score means and standard deviations are presented in Table III, with the mean scores plotted in Figure 1. Anovas indicated a main effect in social competence $(F=5.67, p<.01)$, adaptive functioning $(F=11.78, p<.001)$, the number of teacher reported behavior problem items $(F=7.91$, $p<.01)$, and the teacher reported total behavior problem score $(F=6.81, p<.01)$. Tukey post hoc analyses revealed a significantly $(p<.05)$ higher number of problems for the combined speech and language, and language impaired boys in comparison to the other two groups of boys for adaptive functioning, number of behavior problem items and total behavior problem score on the teacher report form of the Child Behavior Profile. For the parent reported social competence scale, there was a significant difference $(p<.05)$ between the combined speech and language, and language impaired boys and the speech impaired boys, with the latter group showing more developed skills in this area. These results are displayed in Table IV.

To summarize the results to the first question, there were no significant differences in the prevalence of behavioral problems between speech and/or language impaired children and normal children, 
RAW SCORES FOR THE SPEECH IMPAIRED (GROUP I), THE SPEECH AND LANGUAGE, AND LANGUAGE IMPAIRED (GROUP 2), AND NORMAL (GROUP 3) BOYS ON THE CHILD BEHAVIOR PROFILES: MEANS AND STANDARD DEVIATIONS

\begin{tabular}{|c|c|c|c|c|c|c|}
\hline Variable & CBCL & $\begin{array}{l}\text { Group } \\
\text { Mean }\end{array}$ & SD & $\mathrm{N}$ & $\begin{array}{l}\text { Group } 2 \\
\text { Mean }\end{array}$ & \\
\hline
\end{tabular}

$\begin{array}{lllllllllll}\text { Social } & \text { Parent } & 6 & 20.25 & 2.16 & 6 & 15.58 & 2.51 & 12 & 18.54 & 2.52\end{array}$

$\begin{array}{lllllllllll}\text { \# Behavior } & \text { Parent } & 6 & 31.16 & 15.36 & 8 & 29.25 & 13.22 & 14 & 27.71 & 15.38\end{array}$ Problem I tems

$\begin{array}{llllllllll}\text { Total Behavior Parent } & 6 & 36.00 & 18.34 & 8 & 33.75 & 15.73 & 14 & 30.92 & 14.26\end{array}$ Problem

$\begin{array}{llllllllll}\text { Adaptive } & \text { Teacher } 6 & 21.50 & 4.76 & 8 & 10.87 & 4.76 & 14 & 17.71 & 3.68\end{array}$ Functioning

$\begin{array}{llllllllll}\text { \# Behavior } & \text { Teacher } 6 & 3.50 & 2.51 & 8 & 26.00 & 15.78 & 14 & 13.21 & 9.09\end{array}$ Problem I tems

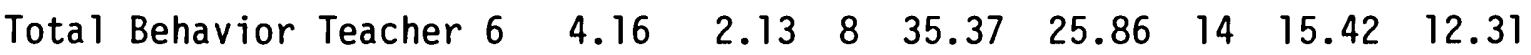
Problem 


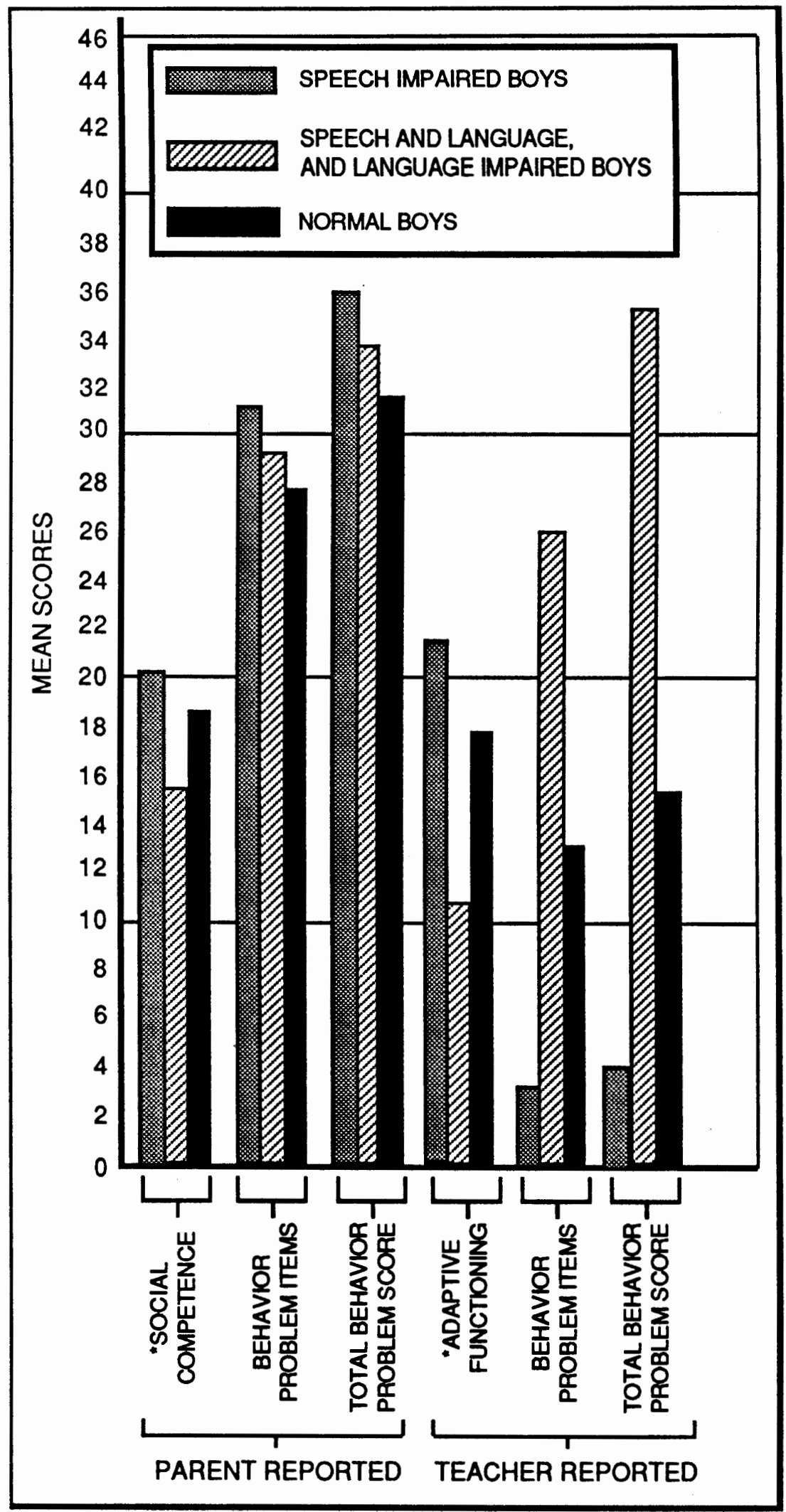

Figure 1. Mean scores on the Child Behavior Profiles for the 3 groups of boys

*Higher score indicates higher competence level. 
TABLE IV

ANALYSIS OF VARIANCE INDICATING DIFFERENCES BETWEEN THE SPEECH IMPAIRED (GROUP 1), THE SPEECH AND LANGUAGE, AND LANGUAGE IMPAIRED (GROUP 2), AND NORMAL (GROUP 3) BOYS

$\underline{\text { Variable }}$

df $\quad \underline{P} \quad \frac{\text { Tukey Post Hoc }}{(p<.05)}$

Social Competence

(Parent)

$235.67<.01^{*} \quad$ Group 2 scored lower than Group 1

Adaptive Functioning (Teacher)

$2711.78<.007^{\star}$

Group 2 scored lower than Groups 1 and 3

\# Behavior Problem

$27 \quad 7.91<.01^{*}$

Group 2 had more problems I tems

(Teacher)

Total Behavior

$276.81<.01^{*}$ than Groups 1 and 3

Problem Score (Teacher)

* Significant 
as reported by parents and teachers. However, when the boys' data were further analyzed by dividing them into 3 groups, the teachers did report a significantly higher number of behavior problems for the speech and language or language impaired boys, and parents reported this group to be less skilled in the area of social competence in comparison to the speech impaired boys.

The second question posed was: Is there a significant difference in types of behavioral problems between speech and/or language impaired children and normal children as reported by parents and teachers? To address this question, the raw scores for each social competence item (parent reported), adaptive functioning item (teacher reported), and the behavior problem scales for both the parent and teacher reported Child Behavior Profiles were analyzed. Each group's raw score means and standard deviations are presented in Tables $V$ and VI for the girls, and Tables VII and VIII for the boys. Anovas for the girls revealed there were no significant differences between the clinic and control groups as reported by the teachers. However, the parents reported a significant difference for the hyperactive behavior problem scale $(F=5.96, p<.05)$ and the social competence item of school performance $(F=8.6, p<.05)$, with the clinic girls having more problems in these areas. Table IX displays these results, with the mean scores plotted in Figure 2. 
TABLE $V$

RAW SCORES FOR THE SPEECH AND/OR LANGUAGE IMPAIRED AND NORMAL GIRLS ON THE PARENT REPORTED BEHAVIOR PROBLEM AND SOCIAL COMPETENCE SCALES: MEANS AND STANDARD DEVIATIONS

\begin{tabular}{lrrrrrr}
\hline Scale & \multicolumn{1}{c}{$\begin{array}{c}\text { Clinic Girls } \\
\text { Mean }\end{array}$} & SD & N & Mean & SD \\
\hline Depressed & 5 & 6.00 & 4.41 & 5 & 2.80 & 3.03 \\
Social Withdrawal & 5 & 3.40 & 2.79 & 5 & 1.60 & 2.60 \\
Somatic Complaints & 5 & 1.20 & 1.30 & 5 & 1.80 & 1.78 \\
Schizoid-0bsessive & 5 & 1.00 & 2.23 & 5 & .20 & .44 \\
Hyperactive & 5 & 8.20 & 5.16 & 5 & 2.00 & 2.34 \\
Sex Problems & 5 & 1.00 & 1.73 & 5 & 1.20 & .83 \\
Delinquent & 5 & 1.00 & 2.23 & 5 & 0 & 0 \\
Aggressive & 5 & 16.40 & 21.99 & 5 & 8.40 & 4.66 \\
Cruel & 5 & 1.20 & 1.78 & 5 & .20 & .44 \\
Externalizing & 5 & 20.20 & 16.39 & 5 & 10.60 & 5.85 \\
Internalizing & 5 & 10.40 & 7.30 & 5 & 6.00 & 4.18 \\
Activities & 5 & 8.70 & 1.30 & 5 & 8.40 & 1.47 \\
Social & 5 & 6.70 & 1.68 & 5 & 8.90 & 2.40 \\
School Performance & 5 & 2.90 & 1.47 & 5 & 5.00 & .61 \\
\hline & & & & & &
\end{tabular}


RAW SCORES FOR THE SPEECH AND/OR LANGUAGE IMPAIRED AND NORMAL GIRLS ON THE TEACHER REPORTED BEHAVIOR PROBLEM AND ADAPTIVE FUNCTIONING SCALES:

MEANS AND STANDARD DEVIATIONS

\begin{tabular}{lrrrrrr}
\hline Scale & N Clinic Girls & & & Normal Girls \\
& & Mean & \multicolumn{1}{c}{ SD } & N & Mean & \multicolumn{1}{c}{ SD } \\
\hline Anxious & 5 & 3.40 & 2.07 & 5 & 2.60 & 2.79 \\
Social Withdrawal & 5 & .80 & .83 & 5 & .60 & 1.34 \\
Depressed & 5 & 2.00 & 1.87 & 5 & .60 & .54 \\
Unpopular & 5 & 1.60 & 1.36 & 5 & 0 & 0 \\
Self-Destructive & 5 & 0 & 0 & 5 & 0 & 0 \\
Inattentive & 5 & 4.20 & 3.19 & 5 & 1.80 & .83 \\
Nervous-Overactive & 5 & .60 & 1.34 & 5 & .60 & .54 \\
Aggressive & 5 & 4.60 & 9.18 & 5 & .60 & .89 \\
Externalizing & 5 & 8.20 & 4.84 & 5 & 2.20 & .37 \\
Internalizing & 5 & 3.60 & 2.30 & 5 & 3.00 & 3.31 \\
School Performance & 5 & 2.93 & 1.36 & 5 & 3.37 & .63 \\
Working Hard & 5 & 4.40 & 1.51 & 5 & 5.00 & .70 \\
Behaving Appropriately & 5 & 4.40 & 1.14 & 5 & 5.00 & 1.00 \\
Learning & 5 & 3.60 & 2.19 & 5 & 5.20 & .83 \\
Happy & 5 & 4.40 & .89 & 5 & 5.40 & 1.34 \\
\hline & & & & & &
\end{tabular}




\section{TABLE VII}

RAW SCORES FOR TIIE SPEECII ANU/OR LANGUAGE IMPAIRED ANU NORMAL BUYS ON TIIE PARENT REPORTED BEIIAVIOR PROBLEM AND SOCINL COMPETENCE SCALES:

MEANS AND STANDARD DEVIATIONS

\begin{tabular}{lrrrrrr}
\hline Scale & N Clinic Boys & & \multicolumn{3}{c}{ Normal Buys } \\
& Mean & SD & Nean & SD \\
\hline Schizoid-Anxious & 14 & 2.28 & 1.68 & 14 & 2.21 & 2.00 \\
Depressed & 14 & 3.92 & 2.94 & 14 & 5.92 & 5.44 \\
Uncommunicative & 14 & 2.42 & 1.78 & 14 & 2.78 & 1.80 \\
Obsessive-Compulsive & 14 & 4.14 & 2.62 & 14 & 3.50 & 3.18 \\
Somatic Conplaints & 14 & .85 & 1.16 & 14 & 1.07 & 1.38 \\
Withdrawn & 14 & 1.92 & 1.49 & 14 & 2.61 & 2.30 \\
Ilyperactive & 14 & 6.28 & 2.49 & 14 & 4.07 & 3.31 \\
Aggressive & 14 & 11.50 & 6.75 & 14 & 9.71 & 6.45 \\
Delinguent & 14 & 2.35 & 2.92 & 14 & 1.71 & 2.39 \\
Externalizing & 14 & 18.85 & 9.72 & 14 & 14.35 & 9.79 \\
Internalizing & 14 & 11.35 & 6.41 & 14 & 12.71 & 9.61 \\
Activities & 14 & 7.35 & 1.33 & 14 & 7.64 & 1.46 \\
Social & 14 & 6.96 & 2.06 & 14 & 6.14 & 1.81 \\
School Performance & 12 & 3.45 & 1.52 & 12 & 4.33 & 1.11 \\
\hline & & & & & &
\end{tabular}


RAW SCORES FOR THE SPEECH AND/OR LANGUAGE IMPAIRED AND NORMAL BOYS ON THE TEACHER REPORTED BEHAVIOR PROBLEM AND ADAPTIVE FUNCTIONING SCALES: MEANS AND STANDARD DEVIATIONS

\begin{tabular}{lrrrrrr}
\hline Scale & Clinic Boys & \multicolumn{4}{c}{ Normal Boys } \\
& N & Mean & SD & N & Mean & SD \\
\hline Anxious & 14 & 1.21 & 1.25 & 14 & 2.07 & 2.12 \\
Social Withdrawal & 14 & 1.07 & 1.77 & 14 & 1.00 & 1.30 \\
Unpopular & 14 & 2.07 & 3.73 & 14 & 1.35 & 2.17 \\
Self-Destructive & 14 & .42 & 1.08 & 14 & .64 & 1.59 \\
Obsessive-Compulsive & 14 & .50 & .85 & 14 & .85 & 1.51 \\
Inattentive & 14 & 8.35 & 9.36 & 14 & 6.21 & 6.94 \\
Nervous-Overactive & 14 & 1.64 & 1.59 & 14 & 1.42 & 1.74 \\
Aggressive & 14 & 9.64 & 14.06 & 14 & 4.78 & 5.83 \\
Externalizing & 14 & 17.50 & 21.78 & 14 & 10.64 & 11.57 \\
Internalizing & 14 & 2.21 & 2.63 & 14 & 2.85 & 2.41 \\
School Performance & 11 & 2.79 & 1.31 & 12 & 2.94 & .68 \\
Working Hard & 14 & 3.85 & 2.21 & 14 & 4.28 & 1.48 \\
Behaving Appropriately & 14 & 3.57 & 1.94 & 14 & 3.85 & 1.40 \\
Learning & 14 & 3.57 & 2.31 & 14 & 4.57 & 1.28 \\
Happy & 14 & 4.42 & 1.39 & 14 & 5.00 & .96 \\
\hline & & & & & &
\end{tabular}


TABLE IX

ANALYSIS OF VARIANCE INDICATING DIFFERENCES

BETWEEN THE CLINIC AND CONTROL GIRLS

\begin{tabular}{llccc} 
Scale & df & $\underline{P}$ & $\underline{\text { Remarks }}$ \\
\hline Hyperactive & 9 & 5.96 & $<.05^{*}$ & $\begin{array}{l}\text { Clinic group had } \\
\text { more problems. }\end{array}$ \\
School Performance & 9 & 8.6 & $<.05^{*}$ & $\begin{array}{l}\text { Clinic group } \\
\text { scored lower. }\end{array}$
\end{tabular}

* Significant

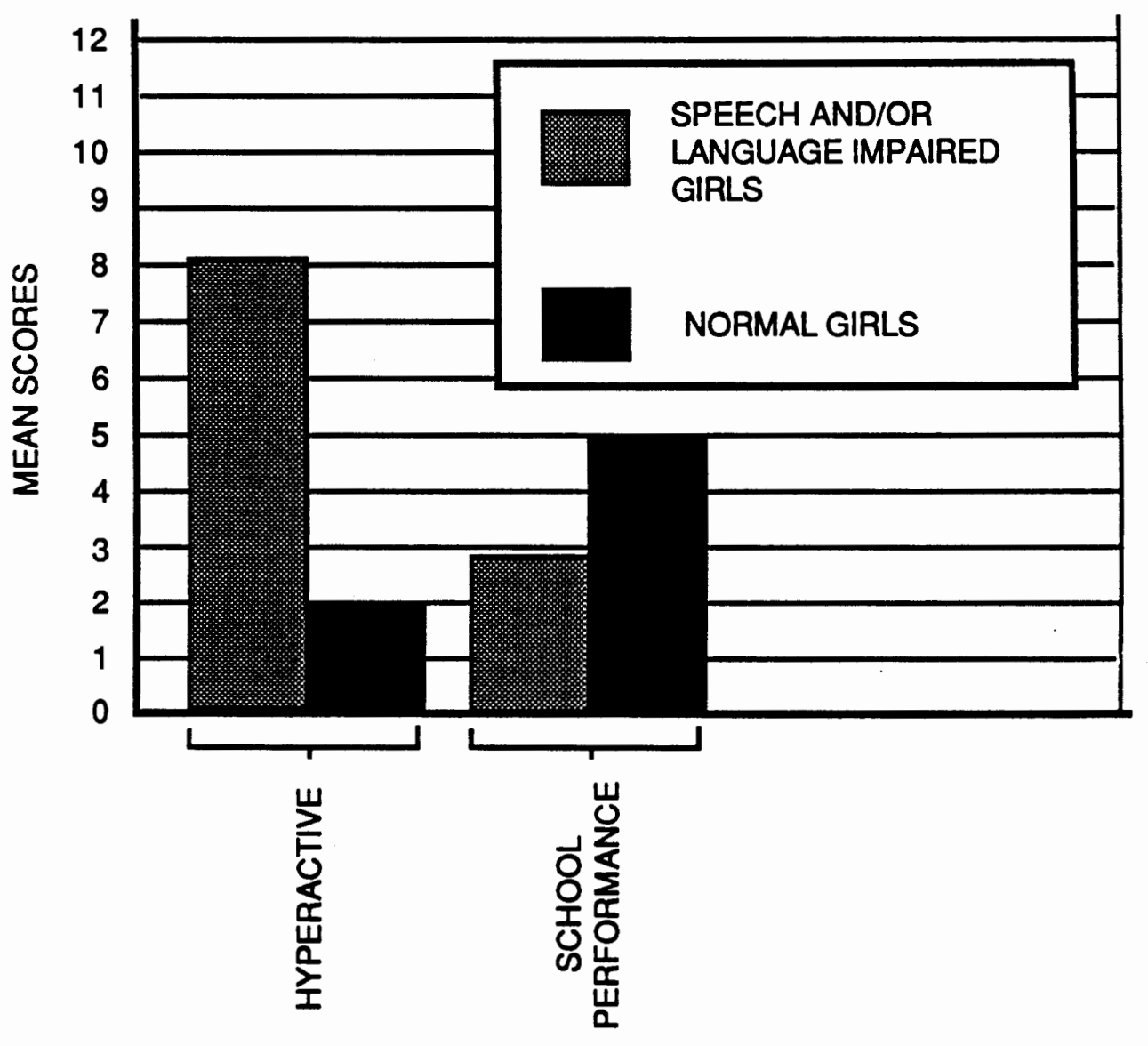

Figure 2. Parent reported differences between the speech and/or language impaired girls and normal girls. 
Anovas for the 2 groups of boys indicated there were no significant differences in types of behavior problems, as reported by parents and teachers. There was a trend toward a significant difference ( $F=$ $3.98, p<.10)$ reported by parents on the hyperactive behavior problem scale, with the clinic group having the higher number of problems. When the boys' data were further analyzed by dividing them into the 3 groups as previously described, significant differences emerged. Each group's raw score means and standard deviations are presented in Tables $X$ and $X I$. Anovas indicated a main effect for the parent reported school performance level $(F=10.61, p<.001)$; the teacher reported behavior problem scales of inattentive $F=6.67, p<.01$ ); aggressive $(F=5.83, p .01)$, and externalizing $F=5.6, p<.01)$, and for the adaptive functioning items of school performance $(F=10.54$, $p<.001)$; working hard $(F=5.76, p<.01)$; behaving appropriately $(F=7.0, p<.01)$; and learning $(F=14.82, \quad p<.001)$. A trend toward significance $(p<.10)$ was found on the teacher reported behavior problem scales of social withdrawal, unpopular, and internalizing with the combined speech and language, and language impaired boys having the most problems. Tukey post hoc analyses revealed a significantly higher $(p<.05)$ number of problems for the combined speech and language, and language impaired boys in comparison to the other 2 groups of boys for both the parent and teacher school performance levels, inattentiveness, aggressiveness and learning. On the teacher reported behavior problem scale of externalizing and on the adaptive functioning items of working hard and behaving appropriately, the combined speech and language, and language impaired group had significantly 


\section{TABLE $X$}

RAW SCORES FOR THE SPEECH IMPAIRED (GROUP 1), THE SPEECH AND LANGUAGE, AND LANGUAGE IMPAIRED (GROUP 2), AND NORMAL (GROUP 3) BOYS ON THE

PARENT REPORTED BEHAVIOR PROBLEM AND SOCIAL COMPETENCE SCALES:

MEANS AND STANDARDS DEVIATIONS

\begin{tabular}{|c|c|c|c|c|c|c|c|c|c|}
\hline \multirow[t]{2}{*}{ Scales } & \multicolumn{3}{|c|}{ Group 1} & \multicolumn{3}{|c|}{ Group 2} & \multicolumn{3}{|c|}{ Group 3} \\
\hline & $\mathrm{N}$ & Mean & SD & $\mathrm{N}$ & Mean & SD & N & Mean & SD \\
\hline $\begin{array}{l}\text { Schizoid- } \\
\text { Anxious }\end{array}$ & 6 & 1.83 & 1.72 & 8 & 2.62 & 1.68 & 14 & 2.21 & 2.00 \\
\hline Depressed & 6 & 5.16 & 3.65 & 8 & 3.00 & 2.07 & 14 & 5.97 & 5.64 \\
\hline Uncommunicative & 6 & 2.83 & 1.83 & 8 & 2.12 & 1.80 & 14 & 2.78 & 1.80 \\
\hline $\begin{array}{l}\text { Obsessive- } \\
\text { Compulsive }\end{array}$ & 6 & 3.33 & 2.50 & 8 & 4.75 & 2.71 & 14 & 3.50 & 3.18 \\
\hline $\begin{array}{l}\text { Somatic } \\
\text { Complaints }\end{array}$ & 6 & .33 & .81 & 8 & 1.25 & 1.28 & 14 & 1.07 & 1.38 \\
\hline Withdrawn & 6 & 1.83 & 1.32 & 8 & 2.00 & 1.69 & 14 & 2.64 & 2.30 \\
\hline Hyperactive & 6 & 5.66 & 2.50 & 8 & 6.75 & 2.54 & 14 & 4.07 & 3.31 \\
\hline Aggressive & 6 & 14.00 & 5.96 & 8 & 9.62 & 7.06 & 14 & 9.71 & 6.45 \\
\hline Delinquent & 6 & 2.50 & 3.01 & 8 & 2.25 & 3.05 & 14 & 1.71 & 2.39 \\
\hline Externalizing & 6 & 20.83 & 9.53 & 8 & 17.37 & 10.23 & 14 & 14.35 & 9.79 \\
\hline Internalizing & 6 & 11.16 & 7.33 & 8 & 11.50 & 6.16 & 14 & 12.71 & 9.61 \\
\hline Activities & 6 & 7.58 & 1.77 & 8 & 7.18 & .99 & 14 & 7.64 & 1.46 \\
\hline Social & 6 & 8.00 & 1.51 & 8 & 6.18 & 2.15 & 14 & 6.14 & 1.81 \\
\hline School & 6 & 4.66 & .87 & 5 & 2.25 & .93 & 11 & 4.33 & 1.11 \\
\hline
\end{tabular}




\section{TABLE XI}

RAW SCORES FOR THE SPEECH IMPAIRED (GROUP 1), THE SPEECH AND LANGUAGE, AND LANGUAGE IMPAIRED (GROUP 2), AND NORMAL (GROUP 3) BOYS ON THE TEACHER REPORTED BEHAVIOR PROBLEM AND ADAPTIVE FUNCTIONING SCALES: MEANS AND STANDARD DEVIATIONS

\begin{tabular}{|c|c|c|c|c|c|c|c|c|c|}
\hline \multirow[t]{2}{*}{ Scale } & \multicolumn{3}{|c|}{ Group 1} & \multicolumn{3}{|c|}{ Group 2} & \multicolumn{3}{|c|}{ Group 3} \\
\hline & N & Mean & SD & $\mathrm{N}$ & Mean & SD & $\mathrm{N}$ & Mean & SD \\
\hline Anxious & 6 & .50 & .83 & 8 & 1.75 & 1.28 & 14 & 2.07 & 2.12 \\
\hline $\begin{array}{l}\text { Social } \\
\text { Withdrawal }\end{array}$ & 6 & 0 & 0 & 8 & 1.87 & 2.03 & 14 & 1.00 & 1.30 \\
\hline Unpopular & 6 & .16 & .40 & 8 & 3.50 & 4.50 & 14 & 1.35 & 2.17 \\
\hline $\begin{array}{l}\text { Self- } \\
\text { Destructive }\end{array}$ & 6 & 0 & 0 & 8 & .75 & 1.38 & 14 & .64 & 1.59 \\
\hline $\begin{array}{l}\text { Obsessive- } \\
\text { Compulsive }\end{array}$ & 6 & 0 & 0 & 8 & .87 & .99 & 14 & .85 & 1.51 \\
\hline Inattentive & 6 & .83 & 1.16 & 8 & 14.00 & 8.78 & 14 & 6.21 & 6.94 \\
\hline $\begin{array}{l}\text { Nervous- } \\
\text { Overactive }\end{array}$ & 6 & .83 & .75 & 8 & 2.25 & 1.83 & 14 & 1.42 & 1.74 \\
\hline Aggressive & 6 & .66 & .81 & 8 & 16.37 & 15.68 & 14 & 4.78 & 5.83 \\
\hline Externalizing & 6 & 1.83 & 1.47 & 8 & 29.25 & 22.61 & 14 & 13.42 & 13.36 \\
\hline Internalizing & 6 & .50 & .83 & 8 & 3.50 & 2.82 & 14 & 2.85 & 2.41 \\
\hline $\begin{array}{l}\text { School } \\
\text { Performance }\end{array}$ & 6 & 3.72 & .84 & 5 & 1.68 & .75 & 12 & 2.94 & .68 \\
\hline Working Hard & 6 & 5.50 & 1.37 & 8 & 2.62 & 1.92 & 14 & 6.28 & 1.48 \\
\hline $\begin{array}{l}\text { Behaving } \\
\text { Appropriately }\end{array}$ & 6 & 5.16 & 1.32 & 8 & 2.37 & 1.40 & 14 & 3.85 & 1.40 \\
\hline Learning & 6 & 5.66 & 1.50 & 8 & 2.00 & 1.30 & 14 & 4.57 & 1.28 \\
\hline Happy & 6 & 5.16 & 1.32 & 8 & 3.87 & 1.24 & 14 & 5.00 & .96 \\
\hline
\end{tabular}


$(p<.05)$ more problems than the speech impaired group. These results are displayed in Table XII with the mean scores for the parent reported school performance levels plotted in Figure 3 , the teacher reported behavior problem scales plotted in Figure 4 , and the adaptive functioning items plotted in Figure 5.

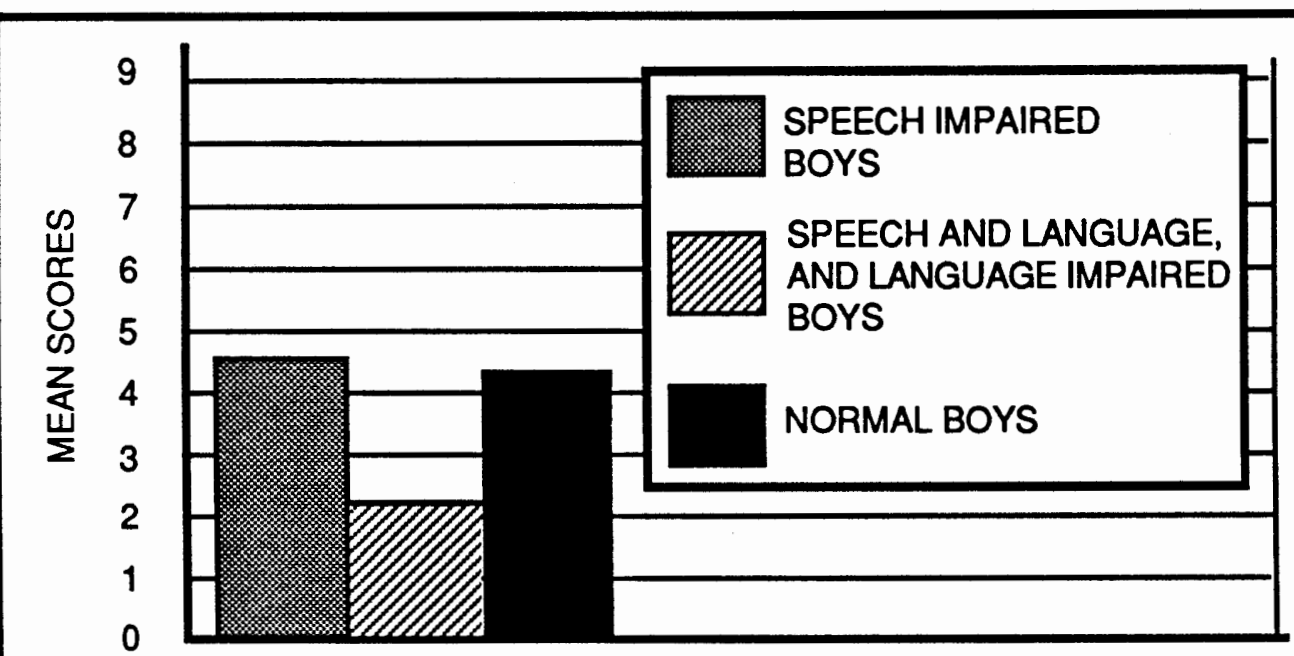

Figure 3. Parent reported school performance levels in the 3 groups of boys. 
ANALYSIS OF VARIANCE INDICATING DIFFERENCES BETWEEN THE SPEECH IMPAIRED (GROUP 1), THE SPEECH AND LANGUAGE, AND LANGUAGE IMPAIRED (GROUP 2), AND NORMAL (GROUP 3) BOYS

Scale

$$
\text { df } \quad \underline{P} \quad \frac{\text { Tukey Post Hoc }}{(p .05)}
$$

School Performance

(Parent)

Inattentiveness

(Teacher)

Aggressiveness

(Teacher)

\section{Externalizing \\ (Teacher)}

School Performance (Teacher)

Working Hard

Behaving

Appropriately

Learning
$23 \quad 10.61$

$276.67<.01$ *

$27 \quad 5.83$

$27 \quad 5.60$

$22 \quad 10.54$

$27 \quad 5.76<.01$ *

$27 \quad 7.00<.0]^{*}$

$2714.82<.007^{\star}$
Group 2 scored lower than Groups 1 and 3

Group 2 had more problems than Groups 1 and 3

Group 2 had more problems than Groups 1 and 3

Group 2 had more problems than Group 1

Group 2 scored lower than Groups 1 and 3

Group 2 scored lower than Group 1

Group 2 scored lower than Group 1

Group 2 scored lower than Groups 1 and 3 


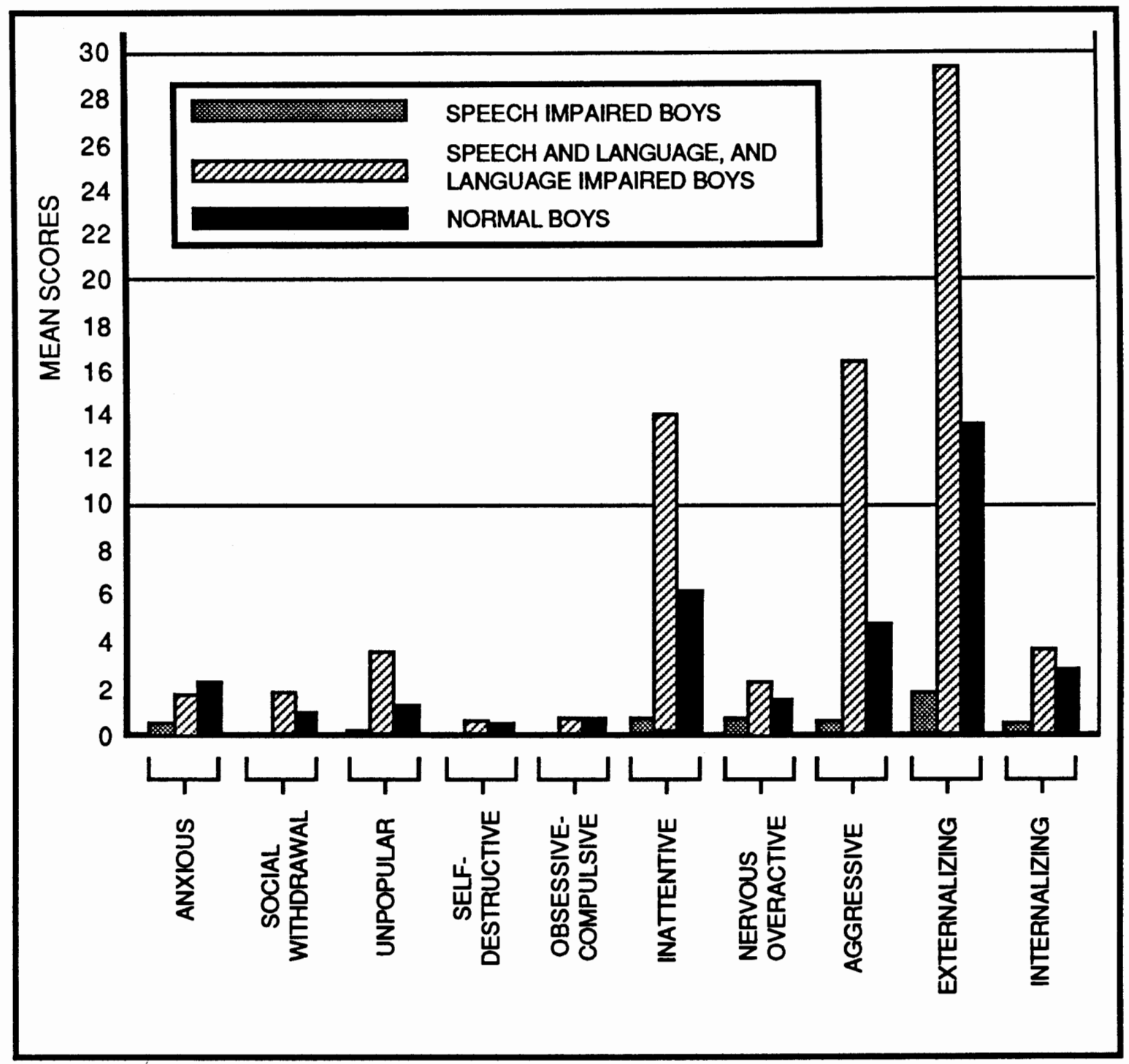

Figure 4. Teacher reported behavior problem scales for the 3 groups of boys. 


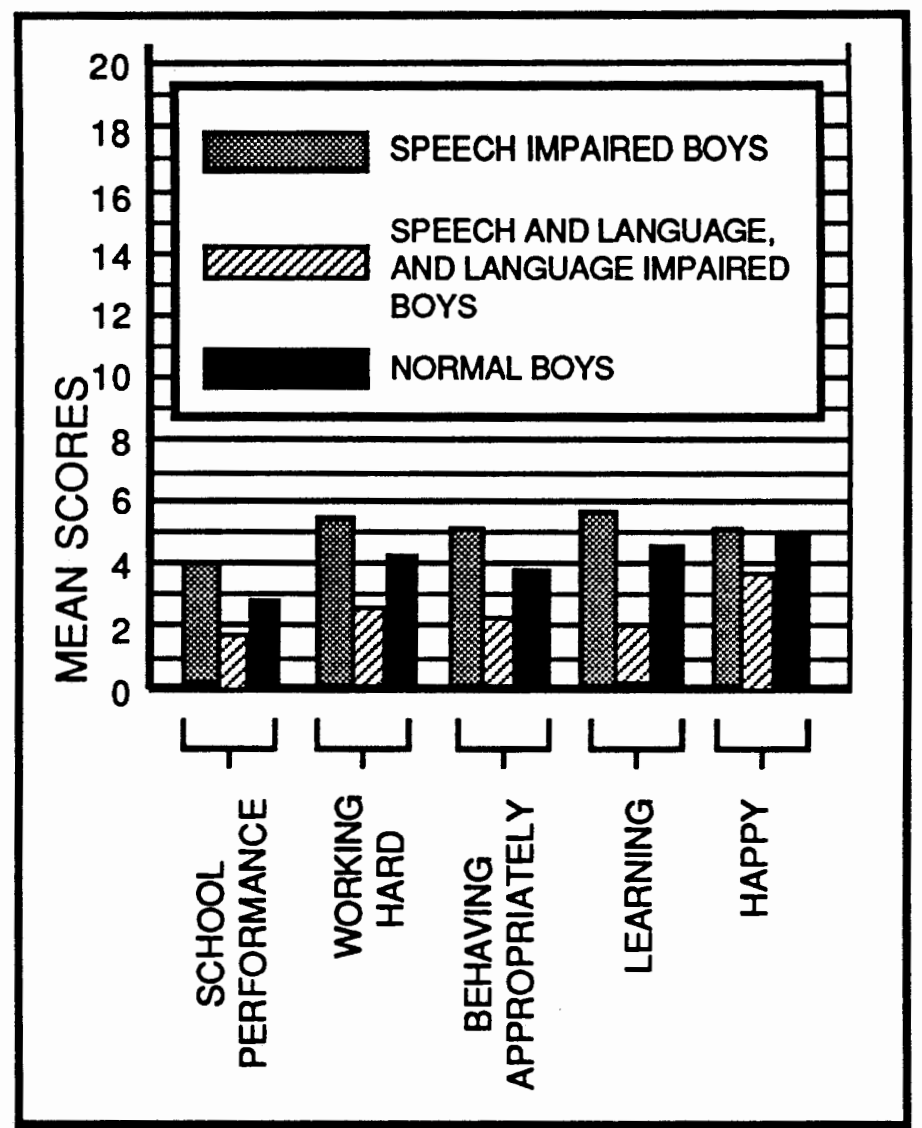

Figure 5. Adaptive functioning items for the 3 groups of boys.

To summarize the results to the second question, there were no significant differences in the types of behavior problems between the speech and/or language impaired girls and normal girls as reported by teachers, but parents described the clinic girls as being more hyperactive and having lower school performance. There were no differences reported for the speech and/or language impaired boys and normal boys. However, when the boys were divided into 3 groups, significant differences were found. 


\section{Discussion}

In addressing the first question the results of this investigation indicated there were no significant differences in the prevalence of behavioral problems between the speech and/or language impaired children and normal children. This finding is contrary to the research cited which found at least a 50 percent occurrence of psychiatric diagnoses in a speech and/or languaged impaired population (Cantwell et al., 1979; Cantwel1 and Baker, 1980; and Baker and Cantwe11, 1980a). Similarly, other studies supported an association between speech and/or language impairment and behavioral problems, which was not found in this investigation (Jenkins et al., 1980; Fitzsimons, 1958; Solomon, 1961; and Stevenson and Richmond, 1978). A possible explanation for this nonsignificant finding is the speech and/or language impaired children may not have been representative of the more severe impairments, and the subjects in the other research cited may not have represented speech and/or language impairments of a less severe nature. To be able to compare findings directiy, more information is needed regarding the severity of problems.

A further explanation may be that one criterion for selection of subjects was different for this study in comparison to the collective research conducted by Baker, Cantwell and Mattison. In this investigation, any speech and/or language impaired child who had an additional handicap (other than learning disability) was excluded, whereas in their research some of their subjects had other handicapping conditions, e.g., autism, mental redardation and hearing impairment. It is possible their finding of at least a 50 percent psychiatric diagnosis 
rate for the speech and/or language impaired subjects is high because of the additional handicaps involved. In addition, all of their subjects had been selected from a community speech and hearing clinic, so they may represent a population with more severe problems. From the research reviewed, it is clear some children with speech and/or language impairments are at risk for behavior problems, however, the results of this study suggest not all speech and/or language impaired children have behavioral problems to a significantly higher degree than their normal peers.

In continuing to address the question of the prevalence of behavioral problems, the boys' data were further analyzed by dividing them into 3 groups. By dividing the clinic group into 2 categories, significant differences were found. The girls group was not divided in the same way due to the small number of subjects, so it cannot be speculated if similar differences would be found. Teachers reported the combined speech and language, and language impaired group as having significantly more problems than the other 2 groups of boys. However, parents did not differentiate the groups in this same way. On the social competence scale, parents reported the speech and language, and language impaired group to be less skilled in comparison to the speech impaired group, but they were not significantly different from the normal boys. Parents did not report any differences with regard to the number of behavior problem items and total behavior problem scores, as the teachers had done. These results are similar to the findings of Baker et al., (1980), in which they compared behavioral problems of children with pure speech disorders and children with disorders with both speech and language. They reported 
teachers found significantly more problems in the speech and language group, but this difference was not reported by the parents. However, their parents did report more severe problems for the speech and language group, which was not found in this study.

An explanation of why teachers reported differences in the combined speech and language, and language impaired group, that were not reported by parents could be due to the educational demands that are being placed upon the child. Language is so central to all tasks involved in school that any deficits in this area for a child could have far reaching effects in how he or she progresses in school, and therefore, behaves in school. The finding that the speech impaired group did not differ significantly from the normal group of boys, suggests language may have been a determining variable associated with a significant increase in behavior problems in the speech and language, and language impaired group. On the contrary, a speech impairment was not a significant variable associated with an increase in behavioral problems. This finding supports the viewpoints of Goodstein (1958); Spriestersbach (1956); and Muma et a1., (1968), who have suggested there are not conclusive data to base any kind of generalizations of personality and behavioral differences of individuals with articulation, voice disorders, or rhythm disorders.

A further inconsistency between the parent and teacher reports of behavior problems was found in the number of behavior problem items and total behavior problems score. Although parents did not report any significant differences among the 3 groups of boys for these variables, the speech impaired boys scored the highest for both, yet 
the teachers reported them as having the least number of problems for these variables. A reason for such a quantitative difference in the number of behavior problem items and total behavior problems score, as reported by the parents and teachers, could be the make-up of the speech impaired group. Of the 6 speech impaired subjects, 2 had participated in a talented and gifted program, and none had an identified learning disability, thus, perhaps this group responded positively to the structure that school provides. Of the 8 speech and language, and language impaired subjects, 3 were learning disabled. It would therefore seem logical that they would have more difficulty in the school environment. Teachers did in fact report an increase in behavior problems for this group. Of the 14 normal subjects, 3 were learning disabled and 2 had participated in a talented and gifted program. Teachers did report fewer problems for this group, although these students still had more problems than the speech impaired group. This result would not support the claims of Beckey (1942), Lindholm and Touliatos (1979), Fitzsimons (1958), and Solomon (1961), that speech impaired children have more behavior problems in comparison to their "normal" peers.

In answering the second question, the results of this investigation indicated there were no differences in types of behavior problems between the clinic and control groups for both the boys and girls, as reported by teachers. However, parents described the clinic girls as being more hyperactive and achieving lower in school performance than the normal girls. Parents reported essentially no differences between the clinic and control boys, except there was a trend toward significance for the hyperactive behavior problem scale, with the clinic boys 
having the higher number of problems. The girls' results revealed another inconsistency between teachers and parents, as the teachers did not report the clinic girls as achieving lower in school performance. In looking at the make-up of the 2 groups of girls, of the 5 clinic girls, 3 were learning disabled and 1 had participated in a talented and gifted program, and of the 5 normal girls, 2 had been involved in a talented and gifted program. With this difference of educational identification between the 2 groups, it is not surprising the parents reported the clinc girls as achieving lower in school performance. What is surprising is that teachers did not report this difference. Perhaps the parents and teachers were using different reference points for comparison. Parents were comparing their children to other children of the same age/grade level, while teachers may have been comparing the students to their own level of potential, so they may have had lower expectations for the learning disabled girls.

Essentially this study found few differences in behavioral problems between the clinic and control groups. This finding is again contrary to the research cited which reported a variety of behavioral problems for speech and/or language impaired children. The behavior checklists used in this study grouped behavior problem items into scales, so the results do not reflect answers to individual questions concerning behavior, but rather to groups of behaviors. This could be one explanation why so many other studies reported a variety of behavior problems for the speech and/or language impaired children, as they have analyzed answers to individual questions. For example, Beckey (1942) reported speech delayed children do not want attention, and they tend to play alone and cry easily. Fitzsimons (1958) reported 
destructiveness, eating problems, fears, jealousy and nervousness as some of the characteristics of children with articulation problems. These studies and others have used specific clinical behavioral symptoms to describe their speech and/or language impaired population, however, the behavior checklists used in this study lends itself more to describing specific clinical syndromes. Therefore, the differences reported in the other studies may have been masked out in this study. However, in the collective research done by Baker, Cantwe 11 and Mattison, an examining psychiatrist made a final diagnosis pertaining to a specific clinical syndrome. Typically, they reported a high number of children with an attention deficit disorder (with a large percentage of them having associated hyperactivity), oppositional disorders and conduct disorders. The only difference in a behavior problem scale found in this study was with hyperactivity reported by parents, so again fewer behavior problems were found for the clinic population. The finding of hyperactivity characterizing the clinic group is in concurrence with other research (Baker et al., 1980; Cantwell and Baker, 1980; Wylie et al., 1965; Stevenson and Richman, 1978; and Caceras, 1971).

As stated, parents reported a higher frequency of hyperactive behaviors for the speech and/or language impaired group. On the teacher reported Child Behavior Profile there is not a corresponding behavior problem scale for hyperactivity, although the scales labeled inattentive and nervous-overactive share some of the same behavior problem items. However, the teachers did not report any significant differences on these behavior problem scales between the clinic and control groups. This could be explained by the fact teachers provide 
a structured environment for learning, perhaps creating an opportunity for the hyperactive behaviors to be channeled.

When the boys' data were further analyzed by dividing them into the 3 groups, more significant differences were found. Teachers reported more problems for the combined speech and language, and language impaired boys on the behavior problem scales of social withdrawal, unpopular, inattentive, aggressive, externalizing and internalizing, and on all of the adaptive functioning items. Parents did not differentiate the groups in the same way, except for school performance level on which they agreed with the teachers that the combined speech and language, and language group performed lower than the other 2 groups. This research substantiates the findings of Baker et al., (1980), Baker and Cantwel1, (1982a), and Baker and Cantwel1 (1982b), that speech and language, and language impaired children have more behavioral problems than speech impaired children. That speech and language, and language impaired children have significantly more problems in school in comparison to the other 2 groups of boys again can be explained by the educational demands which are being placed upon them. Language, an area in which they have deficits, is central to school instruction and learning, thus their school performance is affected and an increase in associated behavior problems is found.

In further evaluating the results of the 3 groups of boys, it was interesting to find on some scales the teachers reported the speech and language, and language impaired boys as being significantly different to the speech impaired boys, but not to the normal boys. On most of the scales, their mean scores were closer to the normal boys, 
than the speech impaired boys. The speech impaired group characteristically had the fewest behavior problems, and were the most competent on the adaptive functioning items. This is contrary to the findings of Lindholm and Touliatos (1979), Fitzsimons (1958), and Solomon (1961), who reported speech impaired subjects had significantly more behavioral problems in comparison to a control group of normal children. Again, this research further supports the opinions of Goodstein (1958), Spriestersbach (1956), and Muma et al., (1968), who contend there is no conclusive data suggesting children with articulation or voice disorders are behaviorally different.

As has been stated, parents and teachers did not agree on the school performance levels for the clinic and control girls. Unlike the parents, teachers did not describe the clinic girls as achieving significantly lower in school. However, parents and teachers did agree on the school performance levels for the boys. They both reported the combined speech and language, and language impaired boys achieved significantly lower on school performance. The discrepency of the teachers failing to report the clinic girls as achieving lower in school performance, suggests perhaps their expectations were lower for the clinic giris, although this was not the case for the boys.

Essentially this study found few differences in behavioral problems between the speech and/or language impaired children and the normal children. However, when the boys' data were further analyzed by dividing the speech and/or language impaired children into 2 categories, significant differences emerged. The speech impaired students did not differ from the normal students, but teachers reported more behavioral problems for the combined speech and language, and 
language impaired group. These children exhibited more problems in the school environment suggesting a deficit in the area of language may have been a determining variable associated with this increase in behavioral problems. 
CHAPTER $V$

SUMMARY AND IMPLICATIONS

Summary

Language is a complex communication system which distinguishes human beings from other species. It is the primary medium through which individuals function and interact in their environment. If a child has any difficulties developing an effective mode of communication, it would seem likely other areas of his or her development could be adversely affected. There is extensive research which shows speech and language disordered children are at risk for behavioral, social and emotional problems (Cantwell and Baker, 1977). It has been suggested at least 50 percent of speech and/or language impaired children may have behavioral problems severe enough as to warrant a definable psychiatric diagnosis (Cantwell et al., 1979). However, it is difficult to assess if this is an accurate prevalence figure because of methodological problems. Their research included speech and/or language impaired children with other handicapping conditions (e.g., autism and mental retardation), so the difficulty then is deciding which handicap is associated with the behavioral problems, the autism/mental retardation or the speech and language impairment. Also, they drew their subjects from a community speech and hearing clinic, a setting which may not reflect a "typical" speech and language impaired population. This research was designed to obtain behavioral data on children, who were selected from a public school 
setting whose primary handicapping condition was speech and/or language impairment, and then compare them to their "normal" peers. This could provide further information to substantiate the claims that a speech and/or language impaired population do in fact have a higher prevalence of behavioral problems.

The questions posed in this study were: 1) Is there a significant difference in the prevalence of behavioral problems between speech and/or language impaired children and normal children as reported by parents and teachers? and 2) Is there a significant difference in the types of behavioral problems between speech and/or language impaired children and normal children, as reported by parents and teachers?

Thirty-eight children between the ages of 5 and 11 participated in this study. The subjects included 19 speech and/or language impaired children and 19 normal children. There were 14 boys and 5 girls in each group. Information regarding the 38 subjects' behavior was obtained by using the parent and teacher reported Child Behavior Checklists developed by Achenbach and Edelbrock (1983).

Results were analyzed by comparing the raw scores in each group on the behavior problem scales, the number of behavior problem items, total behavior problem score, the social competence scale and the adaptive functioning scale. The data for the boys and girls were analyzed separately, as the raw scores were computed on different Child Behavior Profiles. Further analyses were completed on the boys by dividing them into 3 groups: speech impaired only; a combined speech and language, and language impaired group; and the control group of normal boys. These analyses were not completed for the girls 
due to the small number of subjects. Analysis of variance (Anova) and a Tukey post hoc analysis were used to determine whether there were significant differences in the total raw scores between the clinic and control groups.

In addressing the results to the first question, there were no differences in the prevalence of behavioral problems between speech and/or language impaired children and normal children, as reported by parents and teachers. However, when the boys' data were further analyzed by dividing them into 3 groups, the teachers did report a significantly higher number of behavior problems for the speech and language, and language impaired boys, and parents reported this group to be less skilled in the area of social competence in comparison to the speech impaired boys. The results to the second question showed there were no significant differences in the types of behavior problems between the speech and/or language impaired girls and normal girls as reported by teachers, but parents described the clinic girls as being more hyperactive and having lower school performance. There were no significant differences reported for the speech and/or language impaired boys and normal boys, although there was a trend toward significance for the hyperactive behavior problem scale with the clinic boys having the higher number of problems. However, when the boys' data were further analyzed by dividing them into 3 groups, significant differences emerged. The speech and language, and language impaired boys were reported to have significantly lower school performance levels by both the parents and teachers. In addition, the teachers stated they were inattentive, aggressive and had more problems with learning. On the adaptive functioning items of working hard and 
behaving appropriately, and on the teacher reported behavior problem scale of Externalizing, the speech and language, and language impaired group had significantly more problems than the speech impaired group.

\section{Clinical Implications}

The results of this study support the existing research which has shown speech and language, and language impaired children are "at risk" for associated behavioral problems. This has important implications for a speech-language pathologist in both the assessment and remediation of the language impaired child. As many of these children's behavioral problems are manifested in the classroom, an evaluation of the child's language use in this environment seems warranted. This could provide valuable information in learning how the child is using language and in identifying the situations where his or her communication skills seem to break down. From this, an intervention program could be planned to provide the child with functional language skills which could facilitate his or her learning and interaction in the classroom environment. At the same time, an observation of the teacher's language could provide a speech-language pathologist with information to give the teachers feedback if they need to modify their language to more effectively communicate with these language impaired children. In this way, language goals can be planned to focus on building an effective communication system between the child and the teacher, and the child and his or her peers. Providing appropriate language intervention may help alleviate the behavioral problems, as improved language skills may give them coping strategies.

Equally important would be for the speech-language pathologists 
to help identify and refer the language impaired children with behavioral problems to other professionals (e.g., school psychologist, school counselor). A team approach may be most effective in working with the child, as the speech-language pathologist can provide information to the school psychologist/counselor to help them understand the language component of the behavior problem, and they can provide the speech-language pathologist with appropriate techniques to deal with the behavioral problems to minimize interference with learning.

\section{Research Implications}

Further investigation of the association between behavior problems and speech and/or language impairment is indicated. It would be beneficial to replicate this study using a larger sample size, with a severity index for the speech and/or language impairments. Then a comparison could be made across types and severity levels for each speech and/or language impairment. Further definition of this population according to a severity level could help speech-language pathologists become more cognizant of which children are at risk. Using a larger sample size drawn from a public school setting may help in the selection of a more representative sample of a speech and/or language impaired population, and the groups could be divided into 4: speech impaired only; speech and language impaired; language impaired; and, normal children for both the girls and boys. Again, this would help to further define which speech and/or language impaired children are at risk.

In addition, it would be valuable to conduct a longitudinal study of the speech and/or language impaired children with behavioral 
problems to investigate if speech and/or language intervention impacts behavioral changes. 


\section{SELECTED BIBLIOGRAPHY}

ACHENBACH, T. M., \& EDELBROCK, C. (1983). Manual for the Child Behavior Checklist and Revised Child Behavior Profile. U.S.A.: Queen City Printers, Inc.

BAKER, L., \& CANTWELL, D. P. (1982a). Developmental, social and behavioral characteristics of speech and language disordered children. Child Psychiatry and Human Development, 12, 195-206.

BAKER, L., \& CANTWELL, D. P. (1982b). Language acquisition, cognitive development and emotional disorder in childhood. In K. E. Nelson (Ed.), Children's Language, Vol. 3. New Jersey: Lawrence Eribaum Associates, Inc.

BAKER, L., \& CANTWELL, D. P. (1982c). Psychiatric disorder in children with different types of communication disorders. Journal of Communication Disorders, 15, 113-126.

BAKER, L., \& CANTWELL, D. P. (1984). Tangled tongues and troubled tots. Parents Magazine, September.

BAKER, L., CANTWELL, D. P. \& MATTISON, R. E. (1980). Behavior problems in children with pure speech disorders and in children with combined speech and language disorders. Journal of Abnormal Child Psychology, 8, 245-256.

BECKEY, R. E. (1942). A study of certain factors related to retardation of speech. Journal of Speech Disorders, 7 , 223-249.

CACERAS, V. A. (1971). Retardo del lenguaje verbal. Revista Neuropsiquiatria, 34, 210-226.

CANTWELL, D. P., \& BAKER, L. (1983). Depression in children with speech, language, and learning disorders. Journal of Children in Contemporary Society, 51-9.

CANTWELL, D. P., \& BAKER, L. (1980). Psychiatric and behavioral characteristics of children with communication disorders. Journal of Pediatric Psychology, 2, 161-178.

CANTWELL, D. P., \& BAKER, L (1977). Psychiatric disorder in children with speech and language retardation. A critical review. Archives of General Psychiatry, 34, 583-591. 
CANTWELL, D. P., BAKER, L., \& MATTISON, R. E. (1979). The prevalence of psychiatric disorder in children with speech and language disorder: An epidemiological study. American Academy of Child Psychiatry Journal, 18, 450-461.

CHESS, S., \& ROSENBERG, M. (1974). Clinical differentiation among children with initial language complaints. Journal of Autism and Childhood Schizophrenia, 4, 99-109.

CONNERS, C. K. (1969). A teacher rating scale for use in drug studies with children. American Journal of Psychiatry, 126, 884-888.

CONNERS, C. K. (1973). Rating scales for use in drug studies with children. Psychopharmacology Bulletin, 24-59.

EDELBROCK, C., \& ACHENBACH, T. M. (1984). The teacher version of the child behavior profile: I. Boys aged 6-11. Journal of Consulting and Clinical Psychology, 52, 207-217.

FITZSIMONS, R. (1958). Developmental, psychosocial and educational factors in children with nonorganic articulation problems. Child Development, 29, 481-489.

GOODSTEIN, L. D. (1958). Functional speech disorders and personality: A survey of the research. Journal of Speech and Hearing Research, 1, 359-374.

GRIFFITH, C. P. (1969). A follow-up study of children with disorders of speech. British Journal of Disorders of Communication, 4, 46-56.

HOLT, J. (1969). The Underachieving Child. New York: Pitman Publishing Co.

INGRAM, T. T. S. (1959). A description and classification of the common disorders of speech in children. Archives of Disorders in Children, 36, 444-467.

JENKINS, S., BAX, M. \& HART, H. (1980). Behavior problems in preschool children. Journal of Child Psychology and Psychiatry and Allied Disciplines, 21, 5-17.

LINDHOLM, B. \& TOULIATOS, J. (1979). Behavior problems of children in regular classes and those diagnosed as requiring speech therapy. Perceptual and Motor Skills, 49, 459-463.

MATTISON, R., CANTWELL, D. P. \& BAKER, L (1980). Behavior problems in children with speech and language retardation. Child Psychiatry and Human Development, 10, 246-257. 
MUMA, J. R., LAEDER, R. L., \& WEBB, C. E. (1968). Adolescent voice quality aberrations. Personality and social status. Journal of Speech and Hearing Research, 11, 576-582.

PEDDICORD, R. S. (1979). Parent-child conflicts associated with communication disorders. Ear, Nose and Throat Journal, $58,336-339$.

President's Commission on Mental Health. (1978). Report to the President. Washington, D.C.: U.S. Government Printing Office.

RUTTER, M., GRAHAM, P., \& YULE, W. (1970). A Neuropsychiatric Study in Children. Suffolk, England: Lavenham Press Ltd.

RUTTER, M., TIZARD, J., \& WHITMORE, K. (1970). Education, Health and Behavior. London: Longmans Green.

SHEEHAN, J. (1962). Projective studies of stuttering. In E. Phil ip Trapp and Philip Himelstein (Eds.), Readings on the Exceptional Child. New York: Appleton-Century-Crofts, Inc.

SOLOMON, A. (1961). Personality and behavior patterns of children with functional defects of articulation. Child Development, 32, 731-737.

SPRIESTERSBACH, D. C. (1956). Report of research on articulatory disorders and personality. Journal of Speech and Hearing Disorders, 21, 329-335.

STEVENSON, J., \& RICHMAN, N. (1978). Behavior language and development in three-year-old children. Journal of Autism and Childhood Schizophrenia, 8, 299-313.

TRAPP, P. E., \& EVANS, J. (1960). Functional articulatory defect and performance on a nonverbal task. Journal of Speech \& Hearing Disorders, 25, 176-180.

U.S. Department of Labor. (1977). Dictionary of occupational titles.

WEINER, P. S. (1968). The emotionally disturbed child in the speech clinic: some considerations. Journal of Speech and Hearing Disorders, 33, 158-167.

WEISS, C. E., LILLYWHITE, H. S., \& GORDON, M. E. (1980). Clinical Management of Articulation Disorders. Missouri: C. V. Mosby Company,

WIIG, E. H., \& SEMEL, E. M. (1976). Language Disabilities in Children and Adolescents. Ohio: Charles E. Merrill Publishing Co. 
WING, L. (1969). The handicaps of autistic children: a comparative study. Journal of Child Psychology and Psychiatry, 10, 1-40.

WOOD, BARBARA S. (1981). Children and Communication: Verbal and Nonverbal Language Development. New Jersey: Prentice-Ha11, Inc.

WYLIE, H. L., FRANCHACK, P., \& MCWILLIAMS, B. J. (1965). Characteristics of children with speech disorders seen in a child guidance center. Perceptual Motor Skills, 20, $1101-1107$. 
CHILD GEHAVIOR CHECKLIST FOR AGES 4.16

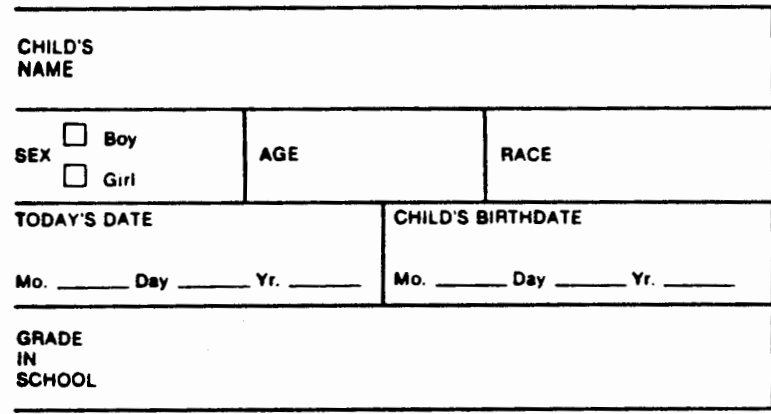

PARENT'S TYPE OF WOAK (Please De spocific-tor example auto mechanic, nigh school teacher, homemakel, haborer, tathe operalor. shoe salesman, army sergeant. even it parent does nol live with child!

\section{FATHER'S \\ TYPE OF WOAK}

MOTHEA'S

TYPE OF WORK:

THIS FORM FILLED OUT BY:
$\square$ mother
$\square$ Father
$\square$ Oiner (Specity)

I. Please list the sporte your chlld most likes Compared to other chlldren of the

to take part in. For example: swimming.

baseball, skating, skate boarding, bike same soe, about how much time riding, fishing, etc.
$\square$ None does heishe spend in each?

Compared to other chlidren of the came age, how well does holshe do each oile?

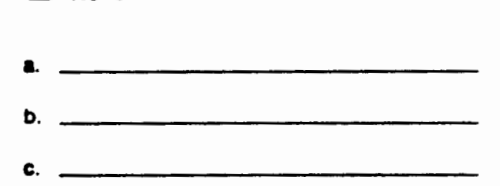
Den'1 Than Averege Mors Know Than Avereos Then Don't Balow Average Above
Know Average $\square \square \square \square$ $\square \quad \square \quad \square$ $\square \square \square \square$ $\square \quad \square \quad \square \quad \square$

II. Please list your child's favorite hobbles, activities, and cames, other then sports. For example: stamps, dolls, books, plano, crafts, singing, etc. (Do not include T.V.)

$$
\square \text { None }
$$

b.

c.

III. Please list any organizations, clubs, leams, or groups your chlid belongs 10.
$\square$ None

$$
\text { a. }
$$

b.

c.

\section{Compared to olther children of the} seme aos, about how much time does helshe spend in each?

Don'l Less
Know Anan Averege
Average
Average

$\square$

$\square \quad \square \quad \square \quad \square$

$\square \square \square \square$

$\square \quad \square$ $\square$
Compared to other children of the same soe, how well does helshe do each one?

Don't Bolow Averege Above
Know Average

$\square \square \square \square$

$\square \square \square \square$

Compared to other chlidren of the came age, how active is halshe in each?

Don't Lees averese More
Know Active

IV. Pleces list any jobs or chores your child has. For example: paper route, babysitting. making bed, etc.

$\square \quad \square \quad \square$
$\square$ None

Compered 10 olher chlldren of the cume age, how wall does helshe carry them out?

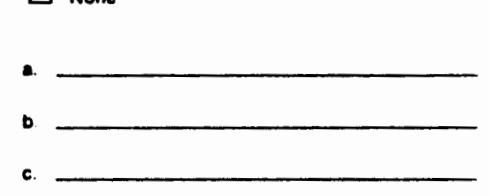


v. 1. About how many close friends does your chlld have? $\square$ None $\square 1 \quad \square 2$ or $3 \quad \square 4$ or more
2. About how many llmos a woek does your chlld do things with them?
$\square$ less than 1
$\square 1$ or 2
D 3 or more

vi. Compared to other chlidren of hls/her age, how well does your child:
1. Get along with his/her brothers \& sisters?
Worse About the same
Bottor
b. Get along with other children?
$\square \quad \square$
$\square$
$\square \quad \square$
c. Bohave with his/her parents?
$\square$
$\square$
d. Play and work by himselt/hersell?
$\square$

$\square$

Vil. 1. Current sehool pertormance-tor children agod 6 and otder:

$\square$ Does not go to school
- Roading or English
b. Writing
c. Arlihmetic or Math
d. Spelling

Other academic sub-

jects-for exemple: his.

tory, science, foreign

language, geography. f.

9.
Falling

$\square$

$\square$

$\square$

$\square$

$\square$

$\square$

$\square$
Bolow average

Averege Abowe averuge

$\square$

$\square \square$

$\square$

$\square$

$\square$

$\square$

$\square \square$

2. Is your ehild in a special clase?

$\square$ No $\square$ Yos-what kind?

3. Has your ehild ever repeated a grede?

$\square$ No $\square$ Yes-grade and reason

4. Mas your child had any ecadomic or other probleme in sehool?

$\square$ No

$\square$ Yes-please describe

When did those problems start?

Have these probleme ended?

$\square$ No $\square$ Yos-when? 
ViI. Below is a list of items that describe children. For each ltem that describes your child now or within the paat 6 months, please circle the 2 if the item is wary trus or often tnis of your child. Circle the 1 if the itern is somowhat or somotimes trus of your chilid. If the item is nol true of your child, circle the 0. Please answer all items as well as you can, even if some do not seem to apply to your child.

$$
0=\text { Nol True (as far as youknow) }
$$
1 - Somowhat or Somotimes True 2 = Very Trus or Otien True

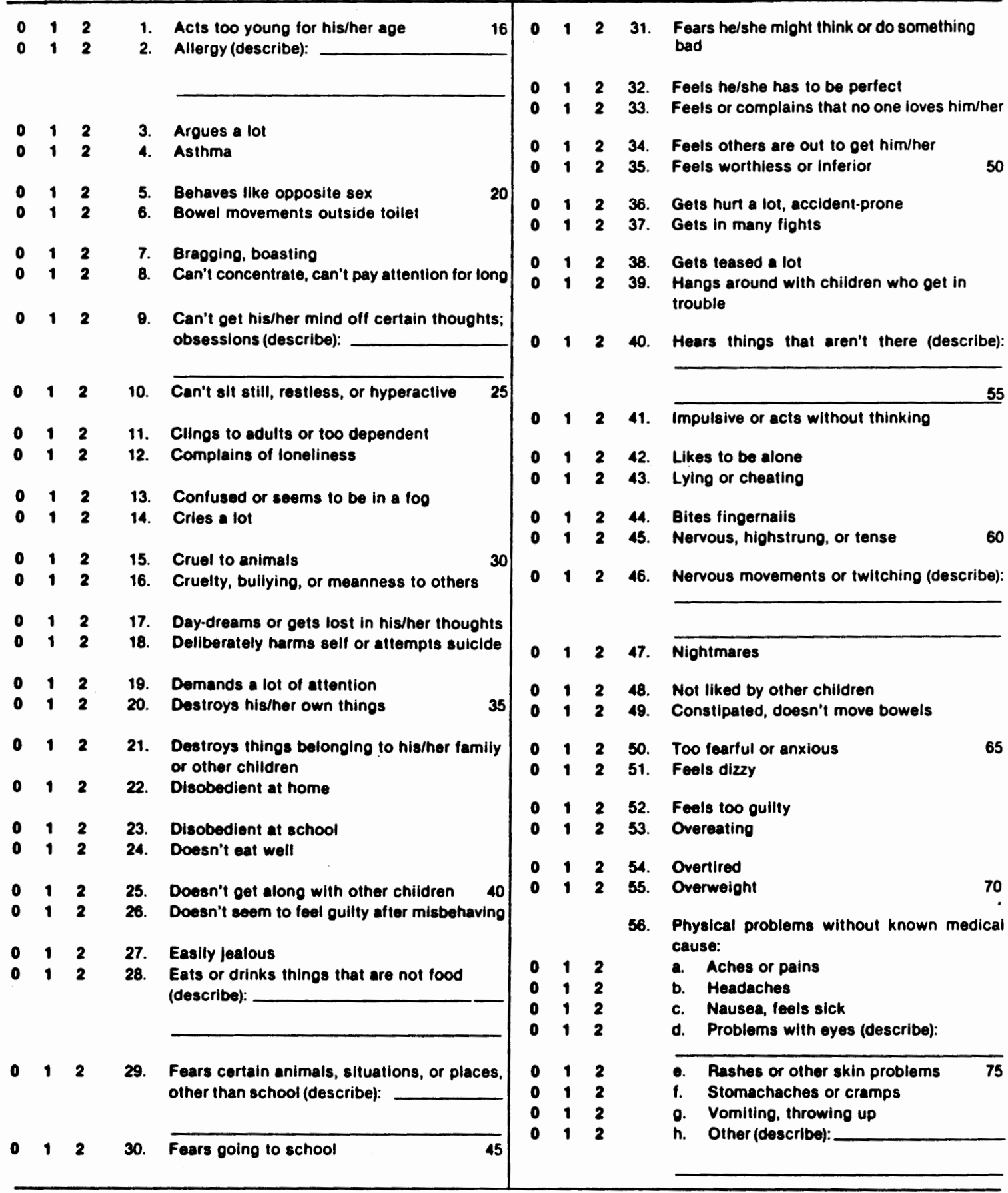




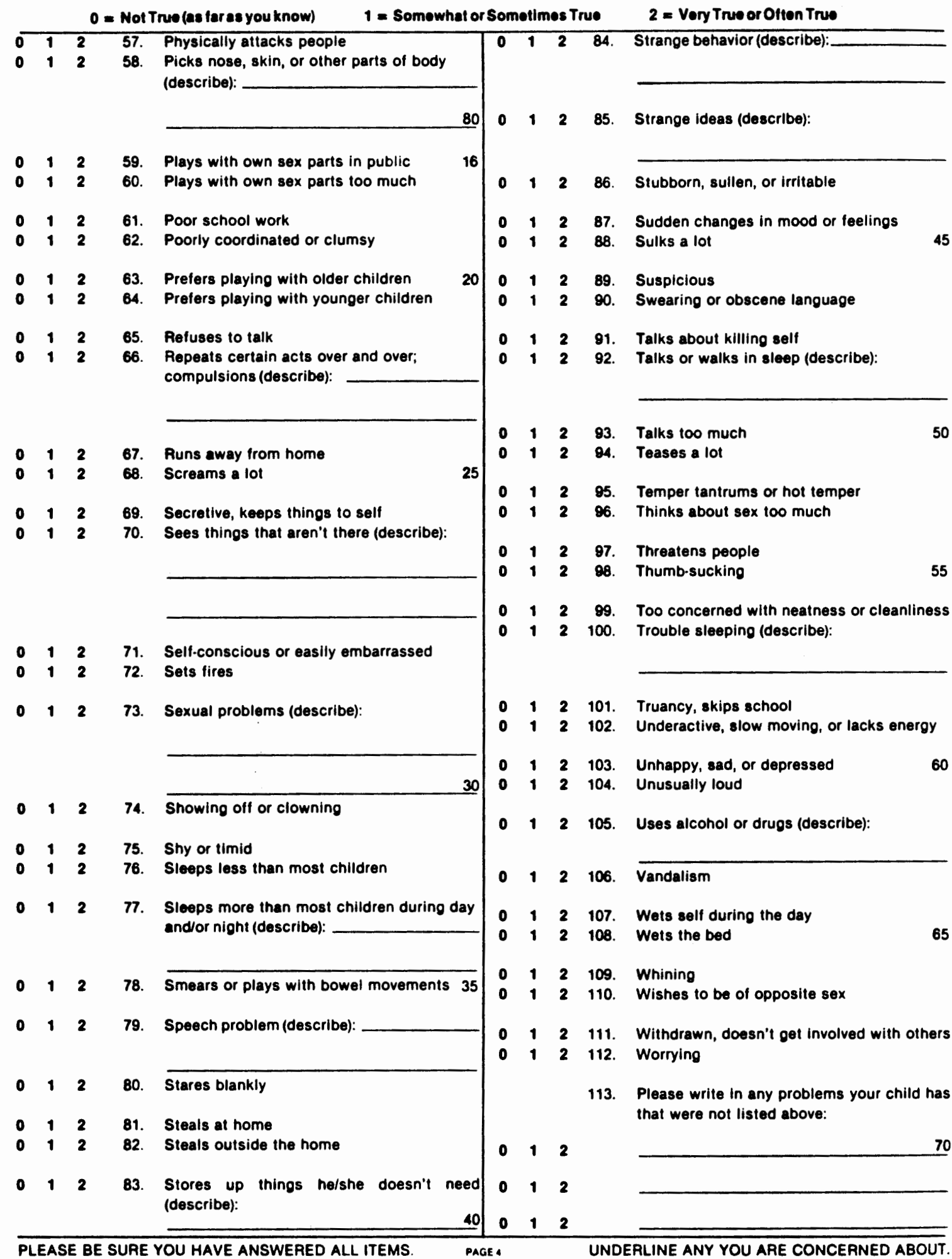




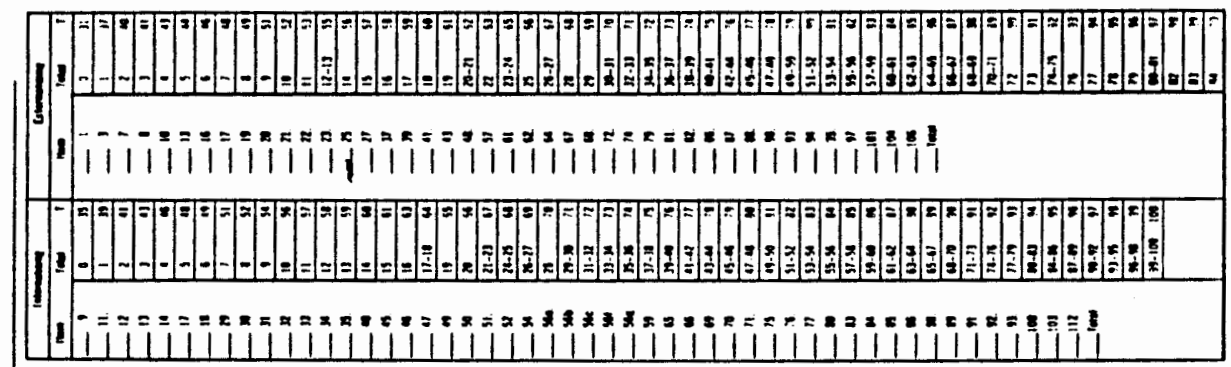

11111111

1 3

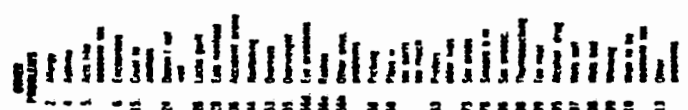

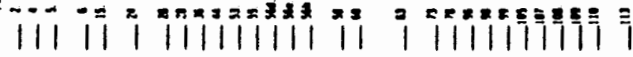

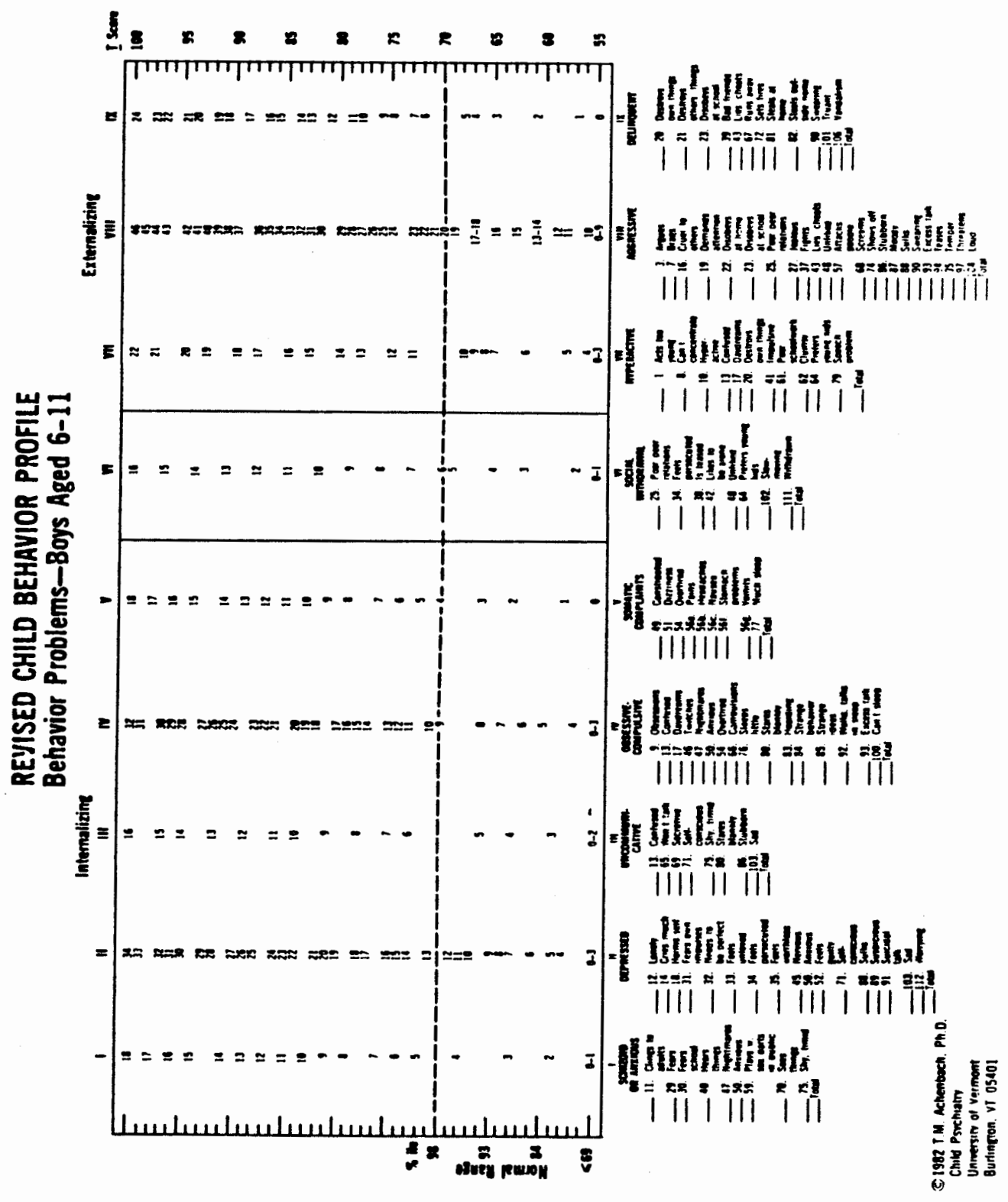


||$_{j}||$

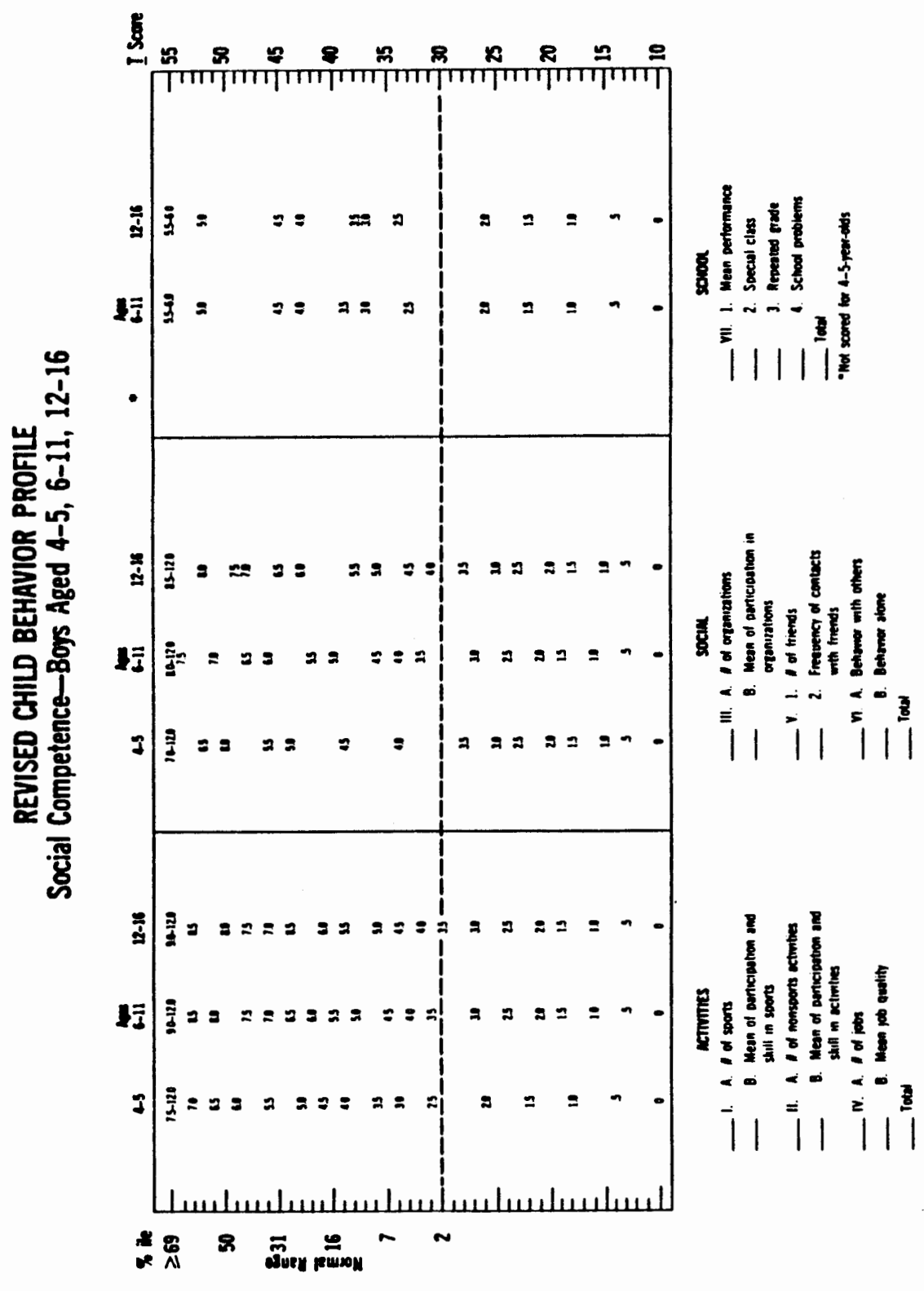




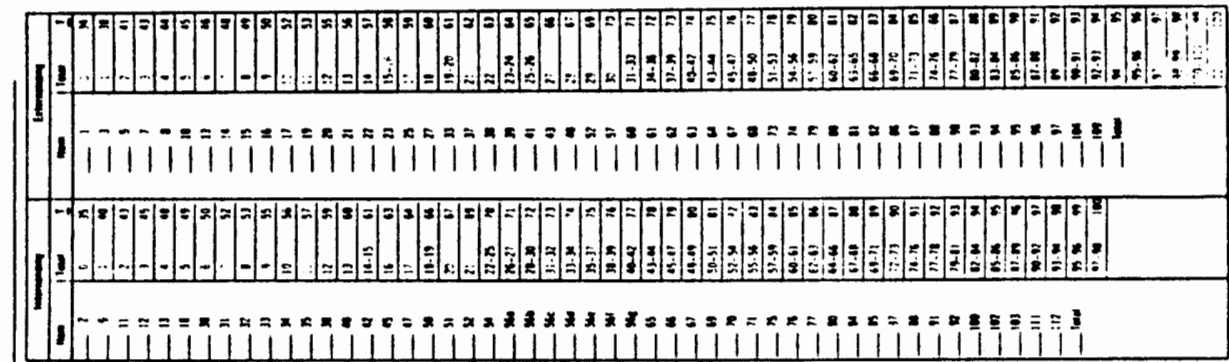

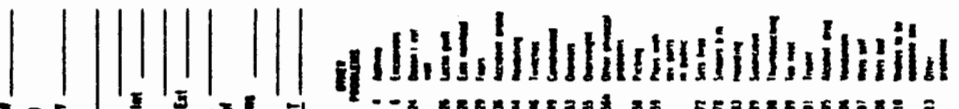

1 I I

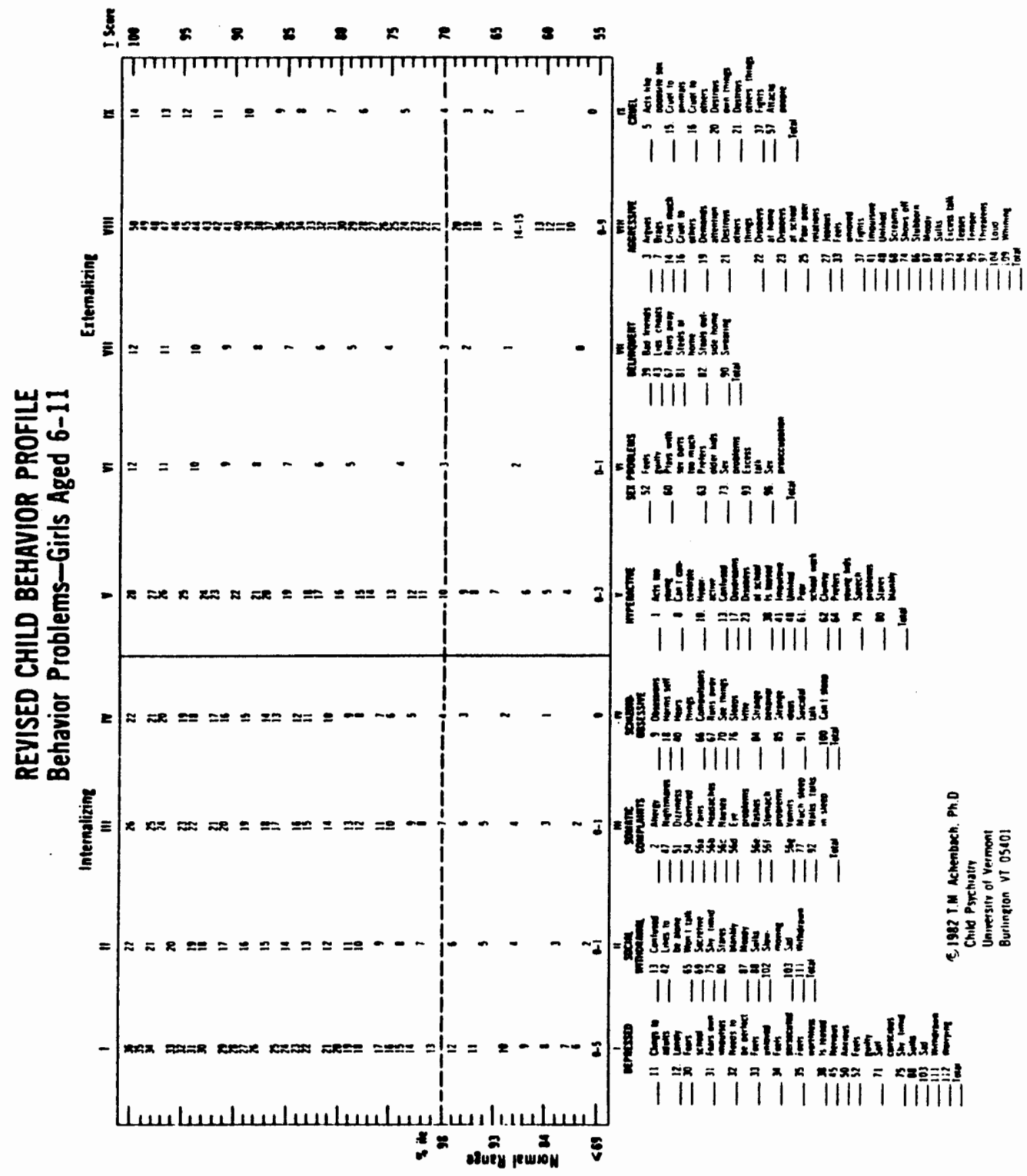



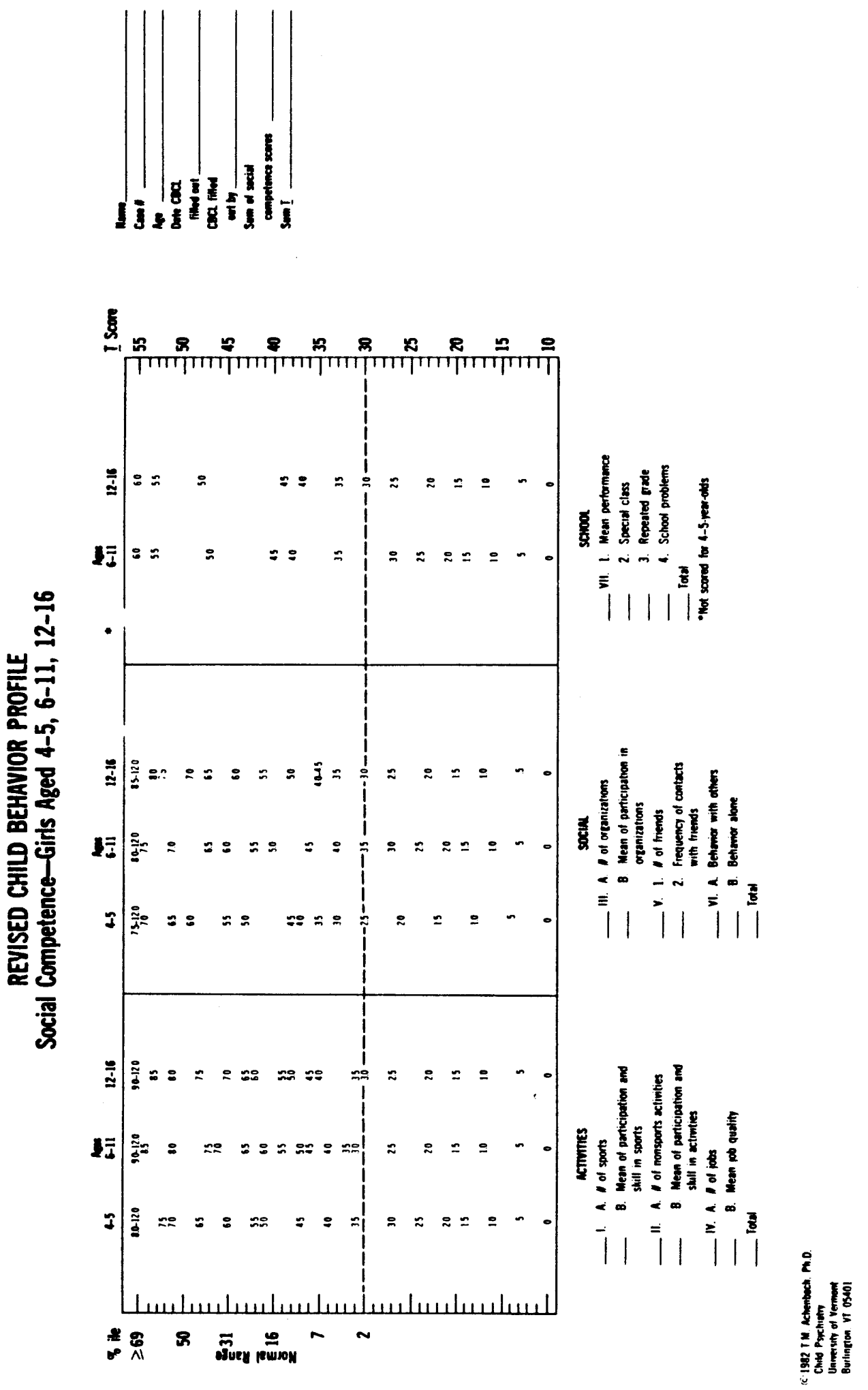


\section{CHILD BEHAVIOR CHECKLIST - TEACHER'S REPORT FORM}

\begin{tabular}{l|l|l|l}
\hline CHILD'S AGE & $\begin{array}{l}\text { CHILD'S SEX } \\
\text { O BOY O Gir }\end{array}$ & RACE & CHILD'S NAME \\
\hline GRADE & $\begin{array}{l}\text { THIS FORM FILLED OUT BY } \\
\text { O Toacher } \\
\text { D Counsalor } \\
\text { D Other (spocity) }\end{array}$ & SCHOOL \\
\hline DATE & & \\
\hline
\end{tabular}

PARENTS' TYPE OF WORK (Plesse be specific - for example, auto mechanic, high school teacher, homemaker, laborer, lathe operator, shoe saleaman, army sergeant.)

FATHER'S

TYPE OF WORK

1. How long have you known thile pupult

\section{How well do you know himstern $\square$ Vary Well $\square$ Moderately Well $\square$ Not Well}

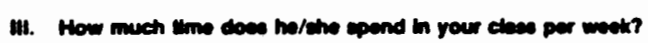

W. Whet idnd of claes is in (Please be epecitic, e.g., regular 5th grade, 7th grade math, etc.)

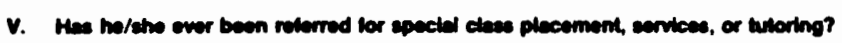
Do
D Dont know
D Yes - what kind and when?

Vi. We mo/ahe ewer mpecied a grade?
D No
D Don't Know
Q Yes - grade and reason

VI. Current echeol pertermance - Vat academic eubjects and chack appropriate column:

\begin{tabular}{|c|c|c|c|c|c|}
\hline Acsodemic subject & $\begin{array}{l}\text { Far bolow } \\
\text { grade }\end{array}$ & $\begin{array}{l}\text { Somminat } \\
\text { below grede }\end{array}$ & Al grade & $\begin{array}{l}\text { Someminat } \\
\text { cbove grede }\end{array}$ & $\begin{array}{c}\text { Far abowe } \\
\text { grade }\end{array}$ \\
\hline 1. & D & 口 & D & D & D \\
\hline 2. & 0 & 口 & a & ס & 口 \\
\hline 3. & D & 口 & 口 & 口 & 口 \\
\hline 4 & 口 & D & D & 口 & ם \\
\hline 5. & 口 & D & 口 & 口 & D \\
\hline 6. & 口 & D & 口 & 口 & D \\
\hline
\end{tabular}




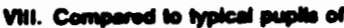
th somesen:

1. How hard is ha/dhe working?

Much

2. How appropriately is ha/ene behaving?

3. How much is ha/aho learning?

4. How happy is ma/ente?

Much

Somewhat bes

D

D

Slightly

lose

D

D

D

D

a

D

D

D

0

About

everage

Slightly

more

Somownat Much

more

D

घ

D

D

口

口

D

D

口

0

D

๑

D

D

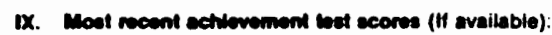

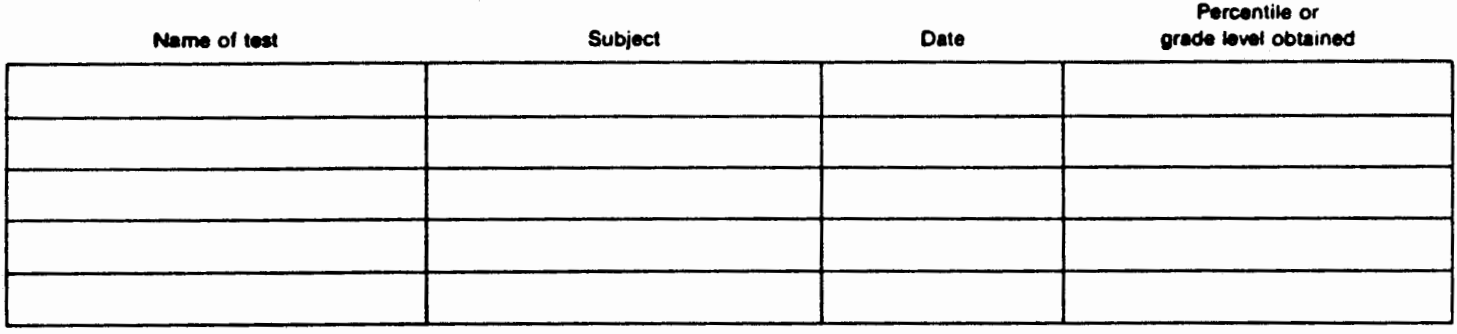

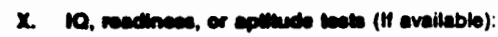

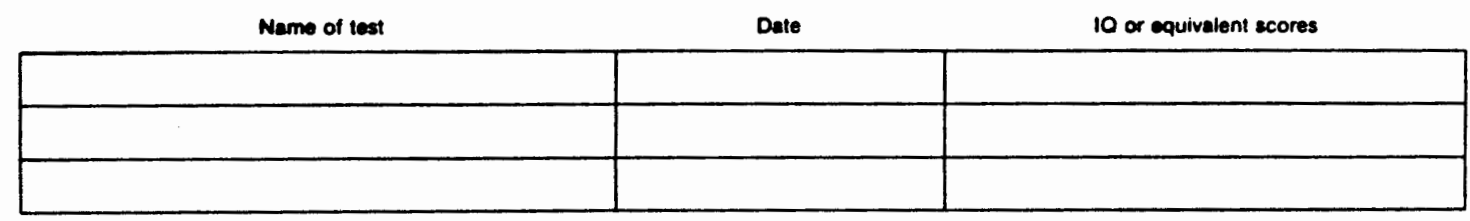

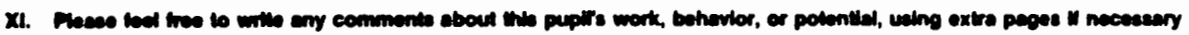


Below is a list of items that describe pupils. For each item that describes the pupil now or whin the peet 2 monthe, plases circle the 2 if the item is very itue or

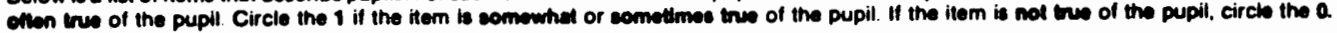

\section{0 - Not True (es far as you know) 1 a Somowhat or Sometimes True 2 = Very True or Olton True}

- 12 1. Acts too young for his/her age

- 12 2. Hums or makes other odd noises in class

- 12 3. Argues a lot

- 14 . Fails to finish things he/she starts

- 12 5. Behaves like opposite sex

- 12 6. Defiant, balks back to staff

- 12 7. Bregging, boasting

- 2 8. Can't concentrate, can't pay attention for long

- 129 Can't get his/her mind ofl certain thoughts: obsessions (describe)

- 12 10. Can't sit still, restiess, or hyperactive

- 1211 . Clings to adults or too dependent

- 1212 . Complains of loneliness

- 1 13. Confused or seems to be in a tog

- 12 14. Cries a lor

122 15. Fidgets

01216 . Cruetty. bullying, or meanness to others

- 1 17. Day-dreams or gets lost in his/her thoughts

- 1218 Daliberately herms self or attempts suicide

- 12 10. Damands a lot of attention

- 1220 . Destroys hia/her own things

- 2 21. Dastroys property belonging to others

- 1222 . Difliculty following directions

- 1223 . Disobediont at school

- 12 24. Disturbs other pupils

- 1225 . Doean't get along with other pupits

- 12 26. Doosn't seam to teal guilty after misbehaving

- 1227 . Easily jealous

- 1228 . Eats or drinks things that are not food (describe)

- 1229 . Fears cortain animals, situafions, or places other than school (deacribe)

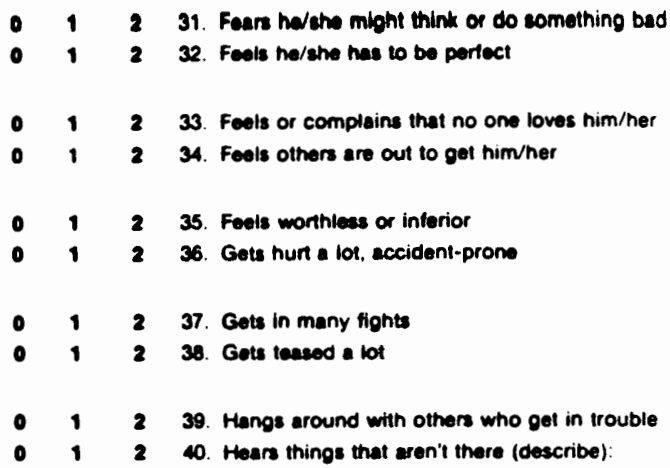

- 124 . Overcontorms to rules

- 1248 . Not liked by other pupils

- 12 49. Has ditticulty karning

- 1250 . Too feartul or anxious

- 1251 . Feels dizzy

1252 Foels too guilty

- 1253 . Talks out ol turn

- 1254 . Oventired

- 1255 . Ovenweight

56. Physical problems without known medical cause:
- Aches or pains
b. Hadaches
c. Noused, teols sick
d. Problems with eyes (describe)
- Rashes or other skin problems
1. Stomachaches or cramps
o. Vomiting. throwing up
h. Other (describo):

- 1230 . Fears poing to echool 
$0=$ Not Irue 1 = Somewhat or Sometimes Irue $2=$ Very Irue or Often Irue

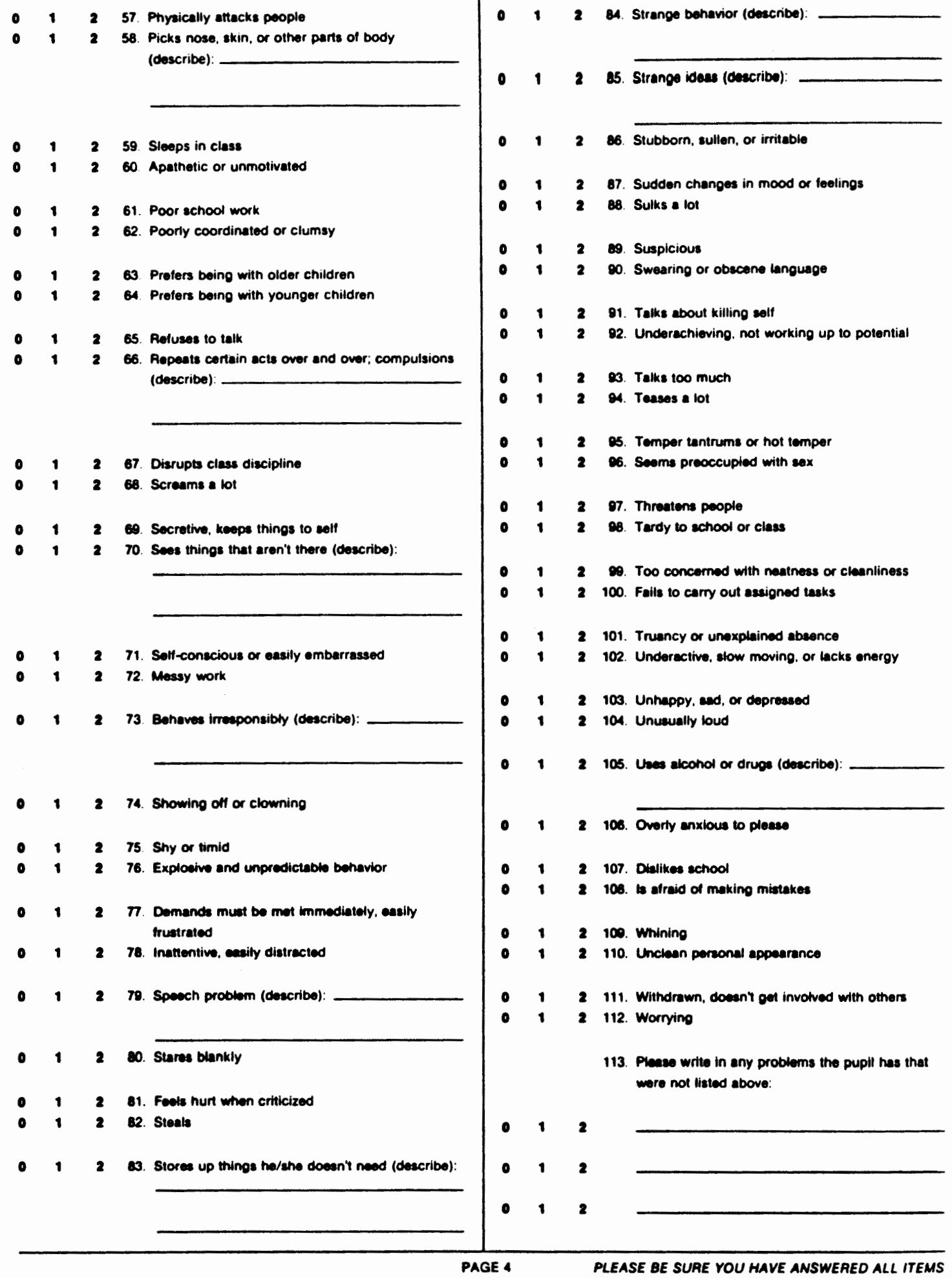




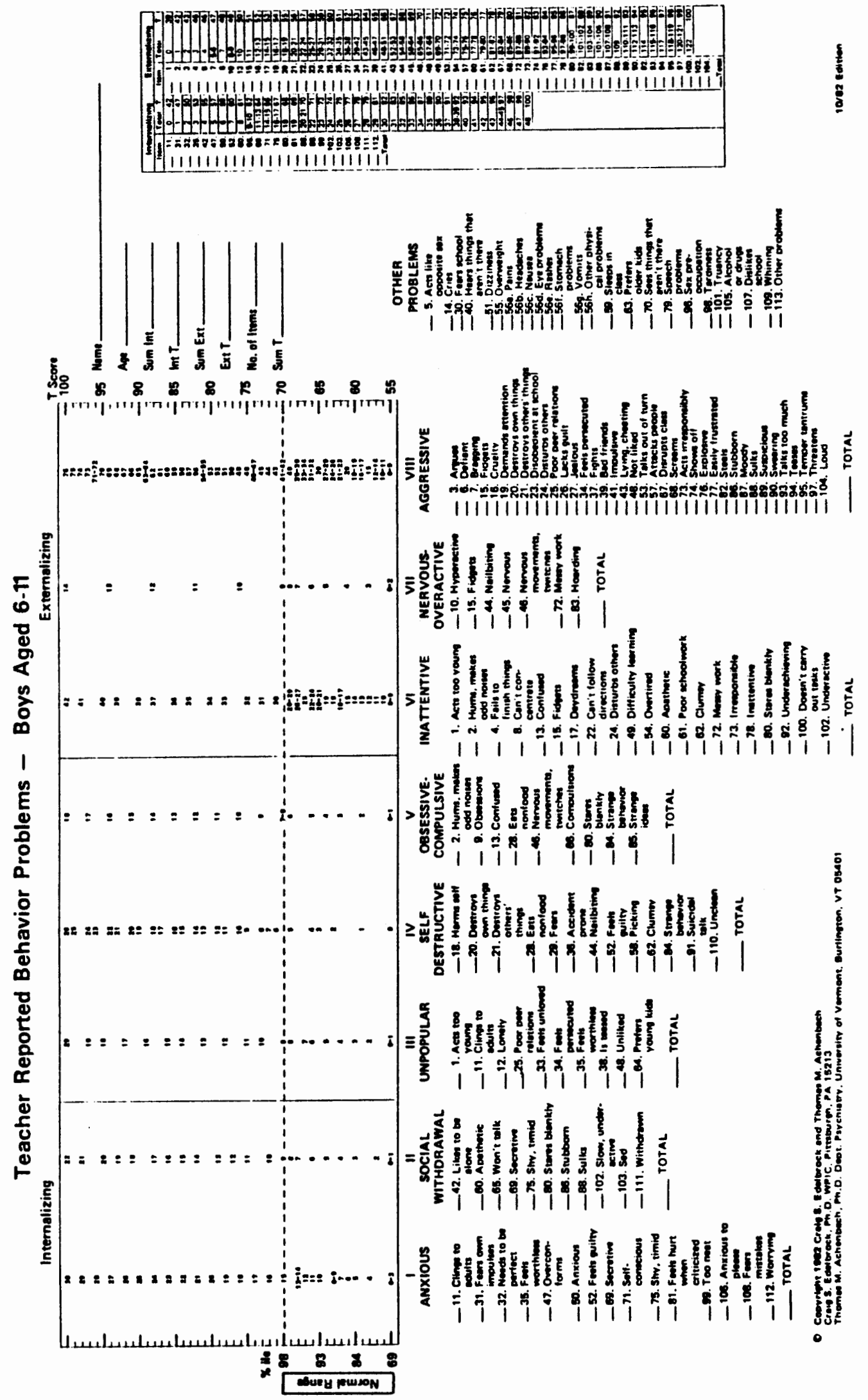




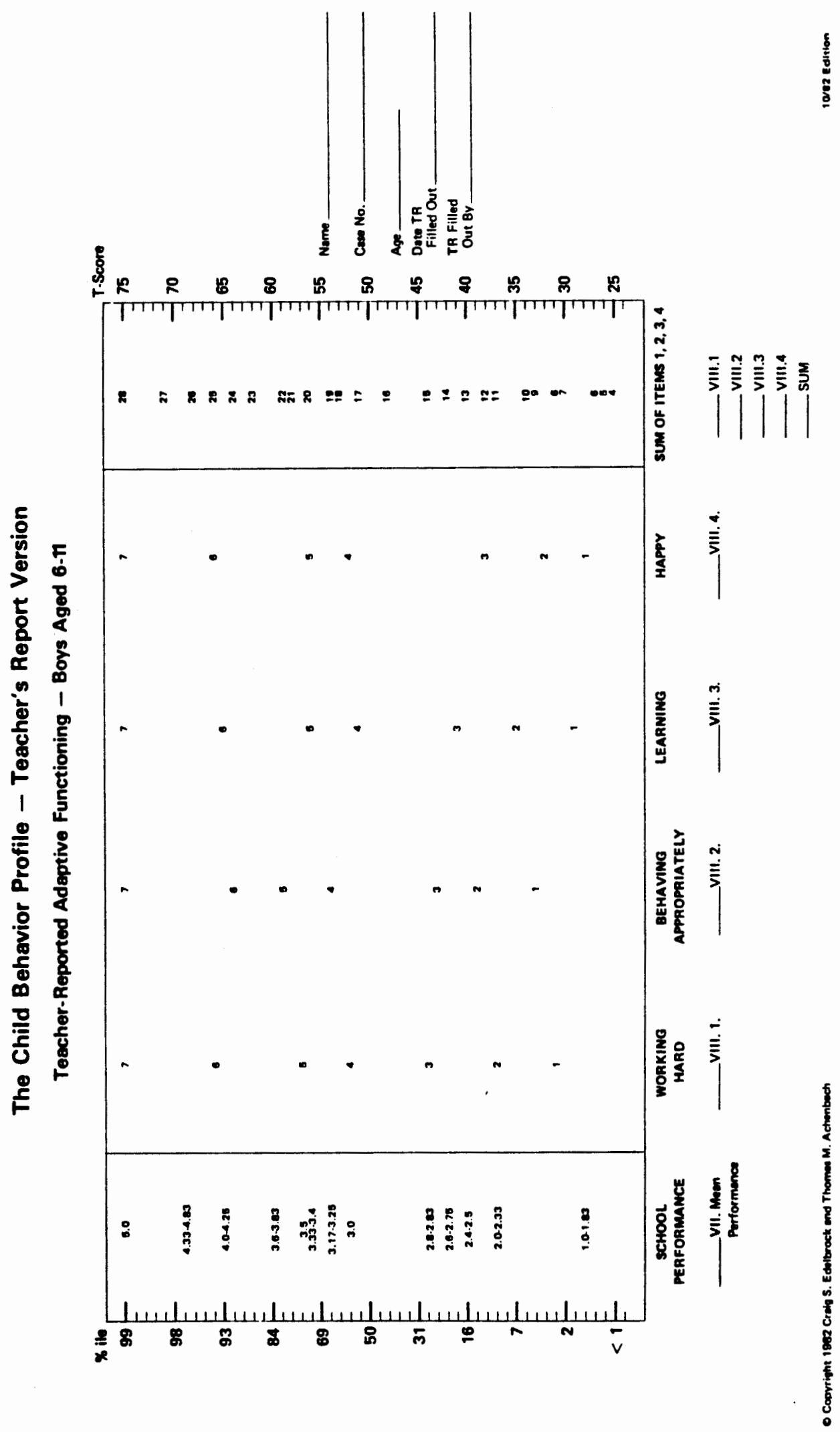




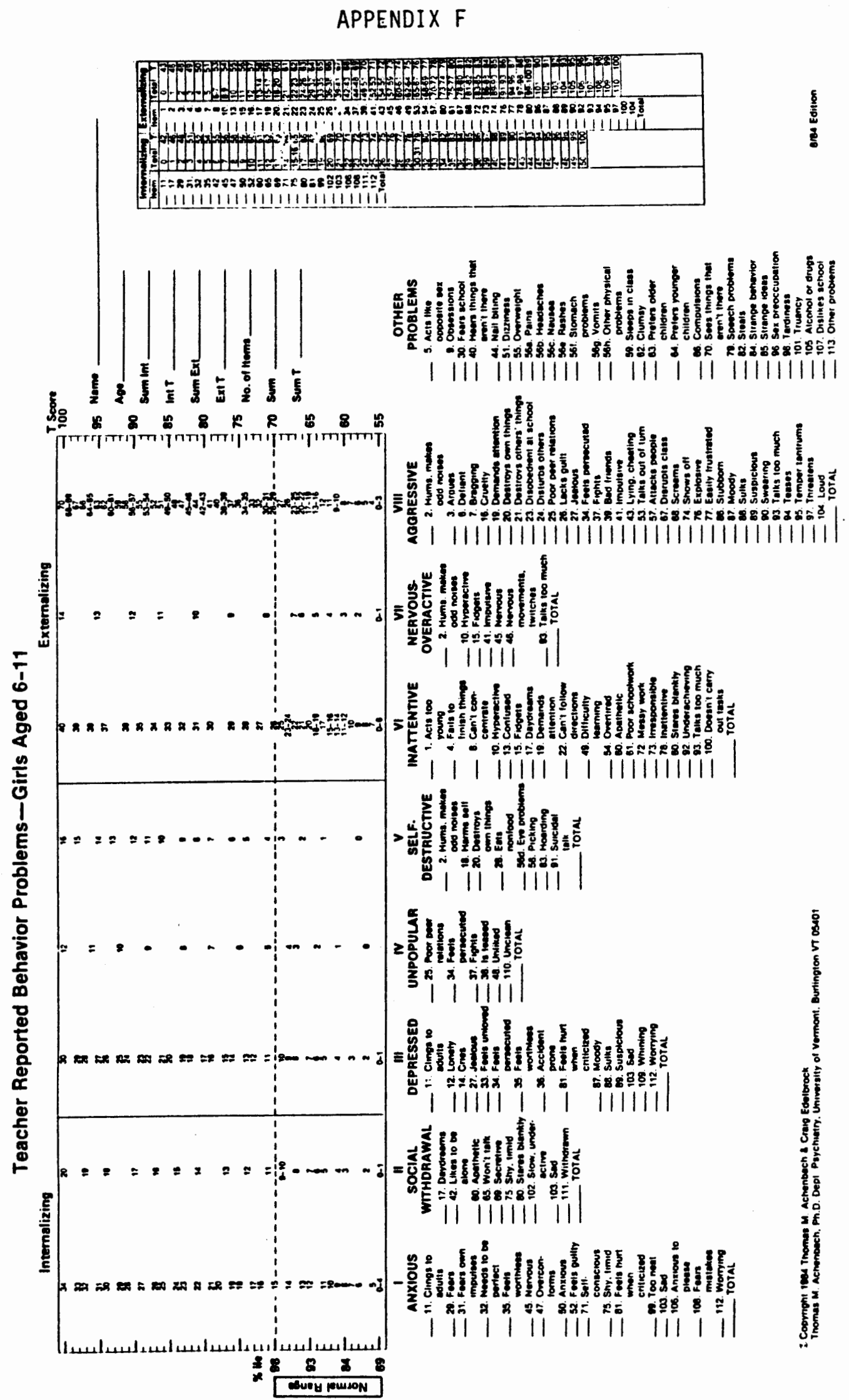




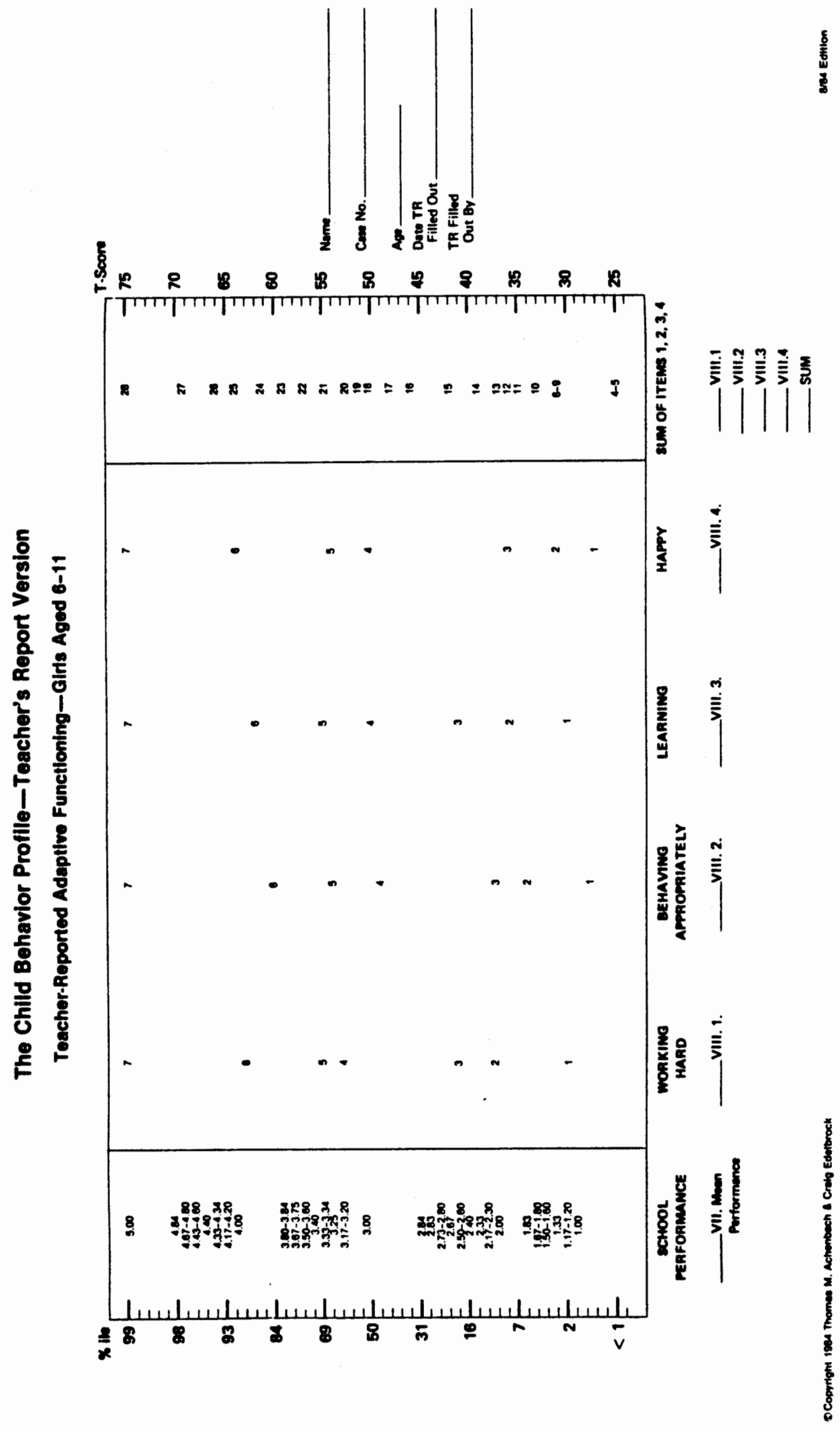




\section{APPENDIX G}

\section{PARENT PERMISSION SLIP}

\section{Dear Parent or Guardian:}

I am a Speech-Language Pathologlst with Centennial School District completing a Master's degree in Speech Fathology at Portland state University. I would like your assistance to help me complete a research project. The purpose of this project is to obtain information about behavior characteristics in school aged children. Ihis information could help in identifying chlldren who are at risk for developing behavior problems which may require professional intervention.

Participation in this project would require an interview with you lasting approximately 15 to 20 minutes. The interview would consist of questions taken from a child behavior checklist designed to obtain information regarding your child's social activities, current school performance, Interactions with other children, and behavior character1stics. In addition, I would interview your chlld's classroon teacher to gather information about your child's behavior at school. Nelther your name or your chlld's name will be used in reporting the results. Complete anonymity is assured. You are free to withdraw from the study at any time without jeopardizing your relationship with Centennial

School District or Portland State University.

If you would $11 \mathrm{ke}$ to particlpate in the study please return the following silp tomorrow, or as soon as possible, to your child's teacher. If you have any ouestions, please reel free to contact me at Lynch Meadows $(760-4070)$.

I would very much appreclate your particlpation in my study. Thank you for your cooperation.

Sincerely,

Jeannle Botelho

Speech-Language Pathologist

Centennial School District

Please sign below to indicate your permission to participate in this study.

Parent's signature Date

Child's signature (1f 7 years or older) Date

Is your child presently recelving services from the school speech-language pathologist? Yes No

$I$, interview my child's classroom hls/her behavior at school. (name), hereby give you permission to teacher to obtain information regarding 


\section{APPENDIX H}

\section{TEACHER PERMISSION SLIP}

\section{Dear Teacher:}

I am a Speech-Language Pathologist with Centennial School District completing a Master's Degree in Speech Pathology at Portland State University. I would like your assistance to help me complete a research project. The purpose of this project is to obtain information about behavior characteristics in school aged children. This information could help in identifying children who are at risk for developing behavior problems which may require professional intervention.

Particlpation in this project would involve you completing a behavior checklist on a few of your students. The checklist is designed to obtain information regarding a child's current school performance and behavior characteristics. In addition, I will be interviewing the child's parents to obtain further information about the child's behavior at home. In reporting the results of my study, your name, the child's or parent's name will not be used, so complete anonymity is assured. I have already obtalned parental consent to jather information from you regarding their child's behavior at school. You are free to withdraw from the study at any t1me without jeopardizing your relationsh1p with Centennial school District or Portland state University.

If you would like to particlpate in this study, please sign the slip below. I would very much appreclate jour particlpation in my study. Thank you for your cooperation.

Sincerely,

Jeannie Botelho

Speech-Languaze Pathologist

Centennial School District

Please sign below to indicate your permission to participate in this study. Date 


\section{APPENDIX I}

\section{One-Week Test-Retest Reliabilities}

\begin{tabular}{|c|c|c|c|c|c|c|c|}
\hline & & Boys & & & Girls & & \\
\hline Behavior Problem & $4-5$ & $6-11$ & $12-16$ & $4-5$ & $6-11$ & $12-16$ & Combined \\
\hline Scales & $N=I I$ & $N=13$ & $N=15$ & $N=13$ & $N=16$ & $N=12$ & Samples \\
\hline Aggressive & .91 & .95 & .87 & .92 & .95 & .93 & .92 \\
\hline Anxious-Obsessive & & & & & & .74 & \\
\hline Cruel & & & & & .94 & .93 & .92 \\
\hline Delinquent & .85 & .95 & .97 & & .94 & .97 & .92 \\
\hline Depressed & .62 & .91 & & .84 & $.90^{3}$ & & .78 \\
\hline \multicolumn{8}{|l|}{ Depressed } \\
\hline Withdrawal & & & & & & .85 & \\
\hline Hostile Withdrawal & & & $.88^{\mathrm{ac}}$ & & & & \\
\hline Hyperactive & & $.92^{\mathrm{ac}}$ & $.90^{3}$ & & .98 & & $.96^{\mathrm{ac}}$ \\
\hline Immature & .87 & & .70 & & & & .81 \\
\hline \multicolumn{8}{|l|}{ Immature- } \\
\hline Hyperactive & & & & & & .82 & \\
\hline Obese & & & & $(.42)$ & & & \\
\hline \multicolumn{8}{|l|}{ Obsessive- } \\
\hline Compulsive & & .82 & $(-.12)$ & & & & .61 \\
\hline Schizoid & & & & & & & \\
\hline (or Anxious) & .81 & .84 & .82 & .65 & & .69 & $.86^{\mathrm{ac}}$ \\
\hline \multicolumn{8}{|l|}{ Schizoid- } \\
\hline Obsessive & & & & & $.79^{\mathrm{a}}$ & & \\
\hline Sex Problems & (.48) & & & $(.52)$ & $(.22)$ & & .68 \\
\hline $\begin{array}{l}\text { Social Withdrawal } \\
\text { Somatic }\end{array}$ & .74 & .90 & & .96 & .87 & & .91 \\
\hline Complaints & .96 & .88 & .93 & .61 & .96 & .79 & .87 \\
\hline Uncommunicative & & .69 & $.82^{\mathrm{ac}}$ & & & & .70 \\
\hline Internalizing & .83 & $.93^{\mathrm{ac}}$ & .83 & .93 & $.93^{\mathrm{a}}$ & .81 & $.82^{a}$ \\
\hline Externalizing & .93 & $.95^{\mathrm{ac}}$ & .90 & $.94^{\mathrm{ac}}$ & .97 & .96 & $.91^{a}$ \\
\hline Total Score & .89 & $.97^{\mathrm{a}}$ & .89 & .95 & $.97^{\mathrm{a}}$ & .87 & $.91^{\mathrm{a}}$ \\
\hline
\end{tabular}

\section{Social Compelence} Scales

Activities

Social

$\begin{array}{ll}.83 & .65 \\ .91 & .84 \\ & .96 \\ .92 & .76\end{array}$

.80
$.89 \mathrm{bc}$
.95

$$
.95
$$

$\begin{array}{ll}.68 & .81 \\ .92 & .98\end{array}$

$.83^{\mathrm{b}}$

School

$.93^{\mathrm{bc}}$

$.92 \quad .98$

Total Score

$.92 \quad .76$

$.93 \quad .80 \quad .91^{\mathrm{bc}}$

Median $r$ for entire Table $=.89$

Mean difference between Time 1 and Time 2 scores $=.7$

Note: Figures in the body of the Table are Pearson correlations of Time 1 vs. Time 2 scores for a sample of nonreferred children. Within each sex/age group, correlations are for raw scores. Correlations in the right hand column are for $T$ scores of combined sex/age groups on scales that are similar in two or more groups. All correlations are significant at $p=.05$ or better, except those in parentheses.

-Time $1>$ Time $2, p<.05$ by $t$ test

'Time $2>$ Time $1, p<.05$ by $t$ test

'When corrected for the number of comparisons, Time 1 - Time 2 difference is not significa ${ }^{d} N$ for combined samples $=$ sum of the $N$ s for samples having reliabilities indicated ; same row as the combined sample. 


\begin{tabular}{|c|c|c|c|c|c|c|c|}
\hline & & Inter & arent $A_{f}$ & reement & & & \\
\hline & & Boy's & & & Girls & & \\
\hline Bchavior Problem & $4-5$ & $6-11$ & $12-16$ & $4-5$ & $6-11$ & $\begin{array}{l}12-16 \\
N-24\end{array}$ & Coimbined ${ }^{d}$ \\
\hline Scales & $N=33$ & $N=78$ & $N=40$ & $N=I I$ & $N=2 I$ & $N=24$ & $\begin{array}{c}\text { Samples } \\
7 \eta^{a}\end{array}$ \\
\hline $\begin{array}{l}\text { Aggressive } \\
\text { Anxious-Obsessive }\end{array}$ & .72 & $.80^{\mathrm{ac}}$ & .74 & .68 & .33 & $\begin{array}{c}.53 \\
(.34)\end{array}$ & \\
\hline Cruel & & & & & .65 & .82 & .69 \\
\hline Delinquent & $.61^{\mathrm{ac}}$ & .83 & .83 & & .87 & .80 & $.78^{\mathrm{ac}}$ \\
\hline Depressed & .68 & .59 & & $(.51)$ & $(.09)$ & & .54 \\
\hline $\begin{array}{l}\text { Depressed } \\
\text { Withdrawal }\end{array}$ & & & & & & (.16) & \\
\hline Hostile Withdrawal & & & .55 & & & & \\
\hline Hyperactive & & .61 & .62 & .74 & .81 & & .65 \\
\hline Immature & $.79^{a}$ & & .71 & & & & .69 \\
\hline $\begin{array}{l}\text { Immature- } \\
\text { Hyperactive }\end{array}$ & & & & & & .66 & \\
\hline Obese & & & & .71 & & & \\
\hline Obsessive- & & & & & & & \\
\hline Compulsive & & .62 & .63 & & & & .57 \\
\hline $\begin{array}{l}\text { Schizoid } \\
\quad \text { (or Anxious) }\end{array}$ & .79 & .54 & .64 & .88 & & $(.06)$ & .53 \\
\hline Schizoid- & & & & & & & \\
\hline Obsessive & & & & & .47 & & \\
\hline Sex Problems & (.32) & & & $(.50)$ & $(.07)$ & & .26 \\
\hline $\begin{array}{l}\text { Social Withdrawal } \\
\text { Somatic }\end{array}$ & .69 & $.62^{\mathrm{ac}}$ & & .83 & .51 & & .58 \\
\hline Complaints & .84 & .47 & .70 & .73 & .73 & (.19) & $.63^{\mathrm{ac}}$ \\
\hline Uncommunicative & & .58 & .69 & & & & .63 \\
\hline Internalizing & .77 & .61 & .71 & .74 & (.35) & (.19) & $.59^{a}$ \\
\hline Externalizing & .74 & $.77^{\mathrm{ac}}$ & .72 & .70 & .55 & .68 & $.75^{\mathrm{ac}}$ \\
\hline Total Score & .75 & .65 & .69 & .64 & $(.40)$ & $(.40)$ & $.64^{a}$ \\
\hline
\end{tabular}

Social Comperence Scales

Activities

Social

$\begin{array}{lll}.47^{\mathrm{ac}} & .54 & .60 \\ .68 & .66 & .72 \\ & .79^{\mathrm{bc}} & .84\end{array}$

$.54 \quad .64^{\mathrm{ac}}$

$.44^{\mathrm{a}}$

School

$\begin{array}{lll}.52 & .67 & .77\end{array}$

$\begin{array}{lll}(.41) & .74^{\text {bc }} & .71 \\ & .91 & .83 \\ & .08)\end{array}$

Total Score

Median $r$ for entire Table $=.66$

Mean difference between mothers' and fathers' scores $=1.2$

Note: Figures in the body of the Table are Pearson correlations of scores from CBCLs filled out by mothers and fathers of clinically-referred children. Within each sex/age group, correlations are for raw scores. Correlations in the right hand column are for $T$ scores of combined sex/age groups on scales that are similar in two or more groups. All correlations are significant at $p=.05$ or better, except those in parentheses.

'Mothers' scores $>$ fathers' scores, $p<.05$

'Fathers' scores $>$ mothers' scores, $p<.05$

'When corrected for the number of comparisons, Mother-Father difference is not significant.

${ }^{d} N$ for combined samples = sum of the $N$ s for samples having reliabilities indicated in the same row as the combined sample. 
Stability and Change for Outpatients over 6 and 18 Months

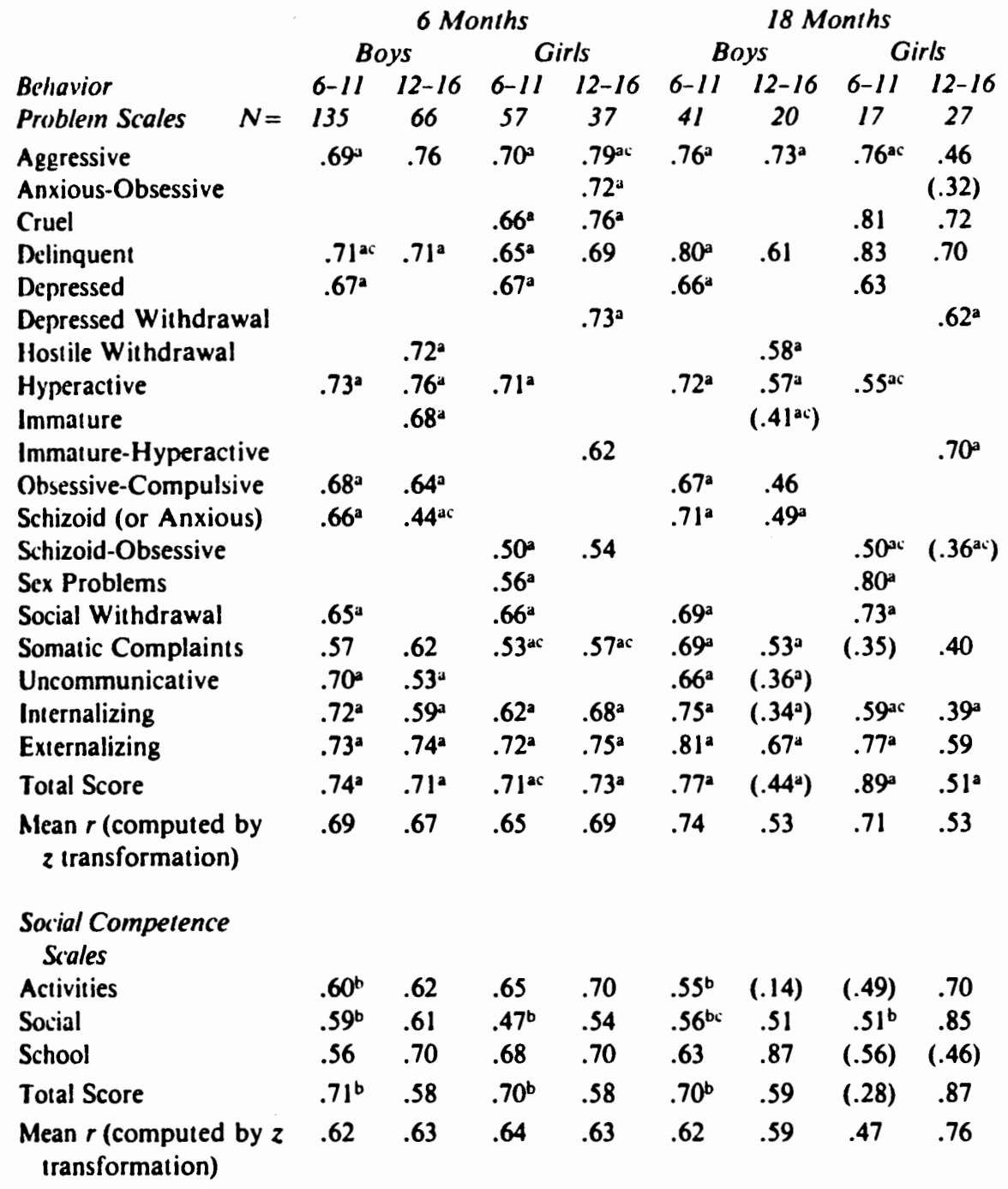

Note-Not enough 4-5-year-olds were available for analysis; all correlations are significant at $p=.05$ or better except those in parentheses; Ns vary within groups because of missing data for some scales.

- Time $1>$ Time 2 or Time 3 significant by 1 lest at $p<.05$.

'Time 2 or Time $3>$ Time 1 significant by $t$ test at $p<.05$.

When corrected for the number of comparisons, difference in means is not significant. 


\section{APPENDIX J}

VALIDITY

Pearson Córrelations Between Child Behavior Profile and Conners Parent Questionnaire

Conners Parents Questionnaire Scale

$\begin{array}{cccc}\begin{array}{c}\text { Child Behavior } \\ \text { Profile }\end{array} & \begin{array}{l}\text { Learning } \\ \text { Problem }\end{array}\end{array}$ Anxiety ionism $\begin{gathered}\text { Psycho- Impulsive- Conduct Anti- } \\ \text { somatic Hyperactive Problem social Total }\end{gathered}$

Boys 6-II

$(N=35)$

School $\quad-.48^{a}$

Schizoid or $\quad .58$

Anxious

Depressed

Obsessive-

.73

Compulsive

Somatic

Hyperactive

Aggressive

Delinquent

Internalizing

Externalizing

.58

Total Problems

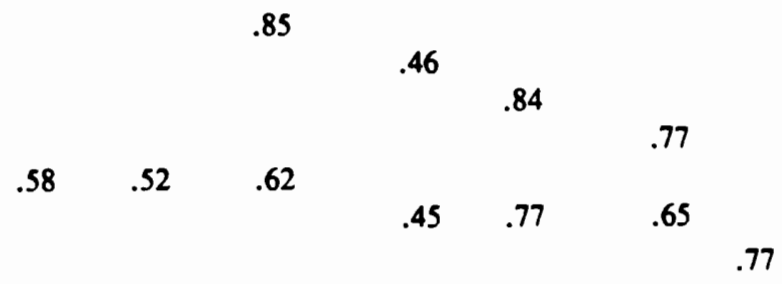

Girls 6-1I

$(N=16)$

School $-.45$

Depressed .70

Somatic Complaints

Hyperactive

Delinquent

Aggressive

Cruel

Internalizing

Externalizing

.44

.44

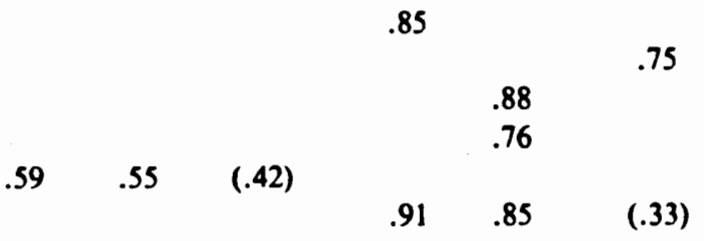

Total Problems

Note-Correlations are between Child Behavior Profile and Conners scales that are most similar in content. All correlations are significant at $p=.05$ or better, except those in parentheses.

- Negative correlation because Profile scale and Conners scale are scored in opposite directions. 
VALIIITY

\section{Pearson Correlations Between Child Behavior Profile and Quay-Peterson Revised Behavior Problem Checklist}

Quay-Peterson Revised Behavior Problem Checklist

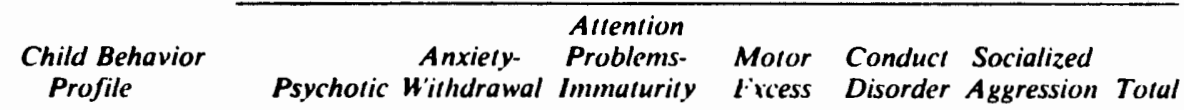

Boj's 6-11 $(N=35)$

Schizoid

.40

.44

or Anxious

Depressed

.78

Uncommunicative

Obsessive-

.62

Compulsive

Social Withdrawal

Hyperactive

.34

Aggressive

Delinquent

Internalizing

.61

Ficess

Disorder Aggression Total

Externalizing

.51

.65

Total Problems

.65

.42

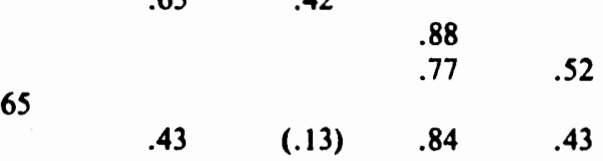

Girls 6-11 $(N=16)$

Depressed Social Withdrawal

Schizoid-

Obsessive

Hyperactive

Delinquent

Aggressive

Cruel

Internalizing

Externalizing

.45

(.26)

Total Problems

\begin{tabular}{|c|c|c|c|}
\hline .88 & .88 & & 80 \\
\hline & & $\begin{array}{l}.82 \\
.68\end{array}$ & .72 \\
\hline .88 & .92 & .77 & .75 \\
\hline
\end{tabular}

Note-Correlations are between Child Behavior Profile and Quay-Peterson scales that are most similar in content. All correlations are significant at $p=.05$ or better, except those in parentheses. 